\title{
EXPTIME Hardness of an $n$ by $n$ Custodian Capture Game
}

\author{
Fumitaka Ito ${ }^{1, t} \neq$, Masahiko Naito ${ }^{1, \ddagger}$, Naoyuki Katabami ${ }^{1, \ddagger}$ and Tatsuie Tsukiji ${ }^{2, *(D)}$ \\ 1 Department of Science and Engineering, Tokyo Denki University, Tokyo 120-8551, Japan; \\ yfa02184@yahoo.co.jp (F.I.); 09udj02@gmail.com (M.N.); stmust@yahoo.co.jp (N.K.) \\ 2 Graduate School of Advanced Science and Technology, Tokyo Denki University, Tokyo 120-8551, Japan \\ * Correspondence: tsukiji@mail.dendai.ac.jp \\ + Current address: Oaza Ishizuka, Hikigun Hatoyama-tyou, Saitama 350-0394, Japan. \\ $\ddagger \quad$ These authors contributed equally to this work.
}

check for

updates

Citation: Ito, F.; Naito, M.; Katabami, N.; Tsukiji, T. EXPTIME Hardness of an $n$ by $n$ Custodian Capture Game. Algorithms 2021, 14, 70. https:// doi.org/10.3390/a14030070

Academic Editor: Frank Werner

Received: 26 January 2021

Accepted: 18 February 2021

Published: 24 February 2021

Publisher's Note: MDPI stays neutral with regard to jurisdictional claims in published maps and institutional affiliations.

\begin{abstract}
Custodian capture occurs when a player has placed two of his pieces on the opposite sides of an orthogonal line of the opponent's men. Each piece moves like the rook in Chess. Different cultures played it from pre-modern times in two-player strategy board games, Ludus Latrunculorum (Kowalski's reconstruction), Hasami shogi in Japan, Mak-yek in Thailand and Myanmar, Ming Mang in Tibet, and so on. We prove that a custodian capture game on $n \times n$ square board is EXPTIME hard if the first player to capture five or more men in total wins.
\end{abstract}

Keywords: computational complexity; custodial capture; EXPTIME hard; generalized game; repetition

\section{Introduction}

Custodial capture occurs on a square lattice board when a player has placed two of his pieces on the opposite sides of an orthogonal line of the opponent's men. Different cultures played it in two-player strategy (i.e., perfect information) board games [1,2]. In A History of Chess [3], after introducing Tafl games in Nordic and Celtic, Murray noted that "the method of capture in this game is identical with that in the unknown Latin game Ludus latrunculorum, in the game which Firdawsi attributes to Buzūrimihr in the Shāhnāma, the Egyptian siga, and a few other Eastern board-games." His other volume, A History of Board Games other than Chess [4], classified battle games "by, first, the method of capture, beginning with those that employ the interception capture-the oldest form of capture in war games - and, second, by the type of move employed." A section titled "Games with interception capture and orthogonal moves" introduced Seega in Egypt, Mak-yek in Thailand, Apit-sodok in Malaysia, Hasami-Shogi in Japan, Gala in Sulawesi, and so on. Hasami-Shogi remains still popular among Japanese children.

Although different cultures specified their own rules, this paper takes the following ones:

R.1 Each player moves one of his pieces in his turn.

R.2 Each piece may move any orthogonal direction and distance with no obstacle (like the rook in Chess).

R.3 When a player succeeds in custodial capturing enemy's men in his turn by moving his piece adjacently next to them, the game removes the men.

R.4 Repeating sequences of moves are prohibited: if the same position of his men occurs three times, by the same player to move, he must vary his choice to avoid the repetition.

R.5 The first player to capture enough total number of an opponent's men throughout the game wins.

They resemble Hasami-Shogi and Ludus latrunculorum (Kowalski's reconstruction). Maak yék (Captain James Low's writing [5]) and Ming Mang [6] have similarities in R.2 and R.3. However, the other reconstructions of Ludus Latrunculorum, Tafl games [7], 
and many others cannot capture multiple men in a line together. These games take the usual starting positions, e.g., placing the all WHITE's (resp. BLACK's) men on the lowest (resp. highest) ranks. They often force the game (without R.4) to be a draw since the players may take defensive strategies that never allow the opponent to capture the player's men.

Once fixing the game rules, combinatorial game theory asks which player to win from the men's given position on the board. The answer may depend on various board sizes and initial configurations specific to each culture. Computational complexity aims to let ideal game machines (i.e., Turing machines) answer this question for any given board size and initial setup. The future machine could be much faster than the current ones, even solving any finite-size problem in a moment, so it concerns $n$ by $n$ board games rather than the finite board ones interesting for human players. Computational complexity classifies them into the hierarchy PTIME $\subset$ PSPACE $\subset$ EXPTIME $\subset$ EXPSPACE. PTIME is the class of problems solvable in polynomial $\left(n^{k}\right)$ time, PSPACE polynomial space, EXPTIME exponential $\left(c^{n^{k}}\right)$ time, and EXPSPACE exponential space (for some constant $c>1$ and $k>0$ ). For example, Chess [8], Checker [9], and Go (Japanese ko-rule) [10] on $n$ by $n$ board are EXPTIME complete. In other words, a machine for $n$ by $n$ Chess solves any EXPTIME problem by playing Chess starting from a position encoding the problem. Consequently, those games' best algorithms might be no faster than searching the vast memory holding all possible $c^{n^{2}}$ positions of the pieces on $n$ by $n$ board, although EXPTIME $\neq$ PSPACE is merely a conjecture. One thing for sure is EXPTIME $\neq$ PTIME, i.e., Chess, Checkers, and Go on $n$ by $n$ board are unsolvable in polynomial time for modern computers. See any computational complexity textbook for more detail, e.g., [11,12].

This paper studies the computational complexity of R.1-R.5 under a straightforward winning rule, the winning number of R.5 is five. It can be any number (no smaller than five) but fixed independently of the number of opponent pieces, although most war games set it equal to (or a few less than) that of the opponent's pieces.

Theorem 1. The custodian capture game of R.1-R.5 on the $n \times n$ square board is EXPTIME hard.

Thus, a simple custodian capture game is as hard to play as modern complex games like Chess, Checker, and Go (Japanese ko-rule) on arbitrary board sizes and configurations.

It could be more complicated since R.4 resembles the Chinese ko-rule of Go, prohibiting to return to any position of the pieces on the board that has occurred previously. Chinese ko-rule Go is EXPSPACE by making an archive of all visited places, whose computational complexity lies anywhere between PSPACE [13-17] and EXPSPACE. Theorem 1 proves the complexity of the custodian capture game between EXPTIME and EXPSPACE using R.4 in essential. Some other games, e.g., Chess [8] and Checker [9], enjoy both EXPTIME completeness by allowing repetition and EXPSPACE completeness by prohibiting it [18].

\section{A Proof Outline}

Stockmeyer and Chandra $[19,20]$ presented the famous $G$-series $\left(G_{1}-G_{6}\right)$ for typical EXPTIME-complete games under log-space many-one reduction. For example, $G_{2}$ in Figure 1 proceeds by alternating turns between WHITE and BLACK, permitting WHITE to switch one of his Boolean (TRUTH or FALSE valued) variables $\left(X_{1}\right.$ or $\left.X_{2}\right)$ or pass (changing no variable) to make his winning formula W-WIN TRUE. BLACK does it for her variables $Y_{1}, Y_{2}$, and formula B-WIN. The first player to make it at the ending of his turn wins. For example, suppose that the $G_{2}$ game starts from $\left(X_{1}, X_{2}, Y_{1}, Y_{2}\right)=$ (FALSE, FALSE, FALSE, TRUE) and WHITE to move. WHITE switches $X_{1}:$ FALSE $\rightarrow$ TRUE to make two $\left(X_{1}\right.$ and $\left.\neg X_{2}\right)$ of the three literals in a term $A_{3}$ TRUE while preserving all $B$ terms of the opponent's 3-term Disjunctive Normal Form (DNF) $B_{1} \vee B_{2} \vee B_{3}$ FALSE even after switching any variable. BLACK responds by $Y_{1}:$ FALSE $\rightarrow$ TRUE for making three $\left(X_{1}, \neg X_{2}\right.$, and $\left.Y_{1}\right)$ of the four literals in $B_{3}$ TRUE, which is a wrong move since $A_{3}$ becomes TRUE; WHITE wins in the next turn by either changing $Y_{2}$ or passing. Stockmeyer and Chandra proved that any of the $G_{i}$ games could simulate any EXPTIME problem by 
adjusting the winning DNFs. Fraenkel and Lichtenstein [8] demonstrated that Chess on $n$ by $n$ board could solve $G_{3}$, so any EXPTIME problem; playing Chess starting from an initial position implementing the $G_{3}$ mechanics forces the players to play the $G_{3}$ game. The previously known EXPTIME-hardness results relied on one of the G-series [8-10,21-23]. We establish Theorem 1 by reducing their $G_{2}$ game to the custodian capture game on the $n \times n$ board with R.1-R.5.

Definition 1 ( $G_{2}$ game). The $G_{2}$ game takes $\langle\tau, W$-WIN $(X, Y), B$-WIN $(X, Y), \alpha\rangle$ for a configuration. It consists of a turn player $\tau \in\{W H I T E(O), B L A C K(\bullet)\}$ making the first move, 12DNF formulae $\tau$-WIN $(X, Y)$ representing $\tau$ 's winning condition, and an initial boolean assignment $\alpha \in\{0,1\}{ }^{X \cup Y}$. From disjoint sets $X$ and $Y$ of boolean variables, WHITE can change only those in $X$, while BLACK can only $Y$. The game starts from a given configuration and proceeds by alternating turns in which turn player changes at most one of his variables. The first player to satisfy his winning condition at the ending of his turn can win the game.

R.5 allows a player to sum up the numbers of men captured in different places and win, making the number of pieces so far captured part of a game configuration. However, it will never happen in our proof, i.e., the players will win by taking enough men at once.

$$
\begin{aligned}
\mathrm{W}-\mathrm{WIN}(X, Y) & =A_{1} \vee A_{2} \vee A_{3} \\
A_{1} & =X_{1} \wedge X_{2} \wedge Y_{1} \wedge Y_{2} \\
A_{2} & =\neg X_{1} \wedge X_{2} \wedge \neg Y_{1} \wedge \neg Y_{2} \\
A_{3} & =X_{1} \wedge \neg X_{2} \wedge Y_{1}
\end{aligned}
$$

Figure 1. An instance of $G_{2}$.

\section{Gadgets in Dead-Lock}

R.1 and R.2 of the custodian capture game provide a high degree of freedom to choose whichever men to move toward orthogonal directions and how long-distance with no other men. We will build a configuration of the custodian capture game so that player $\tau$ can move none of his men in the initial position, called dead-locked pieces, excepting the only one man, named the free $\tau$. The players must play an escape-and-chase game of moving only their free men. We can build all gadgets (groups of pieces placed on the game board) using W-walls (Figure 2) and its dual B-walls (Figure 3), abbreviated by Figures 4 and 5, respectively. These walls tesselate the entire game board by chess-board symmetry. Although we give only one Figure for each gadget, the game configuration may draw the dual (i.e., swapping $\mathrm{O} \leftrightarrow \mathbf{0}$ ), horizontal, or vertical symmetric images.

Definition 2. A gadget is dead-locked if so are all belonging men: Moving any $\tau$ 's man in it forces $\tau$ 's defeat within a few turns.

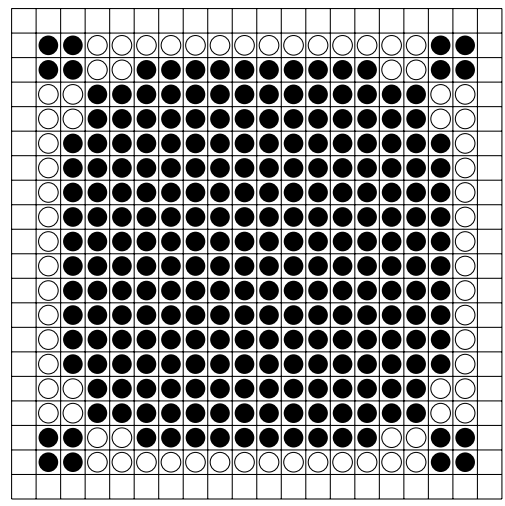

Figure 2. W-wall. 


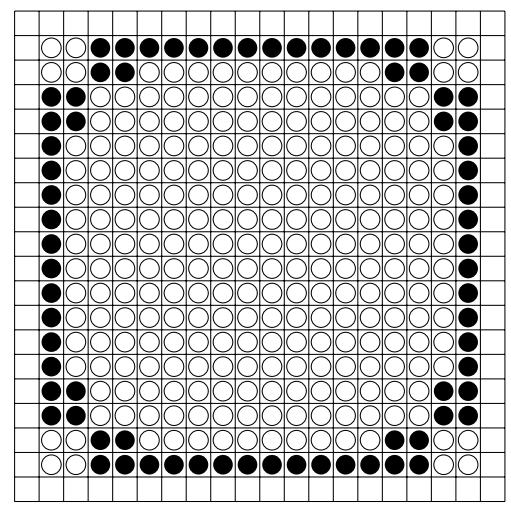

Figure 3. B-wall.

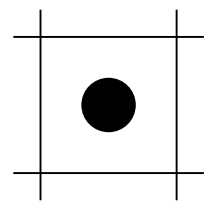

Figure 4. W-wall, abbrev.

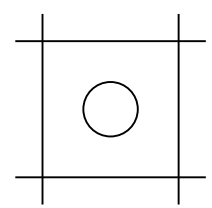

Figure 5. B-wall, abbrev.

\subsection{Corridors}

Figure 6 provides a base gadget to make all other gadgets from its modifications. They fill the entire gameboard by laying the minimum blank squares, the gray zone called a passage, to separate the walls.

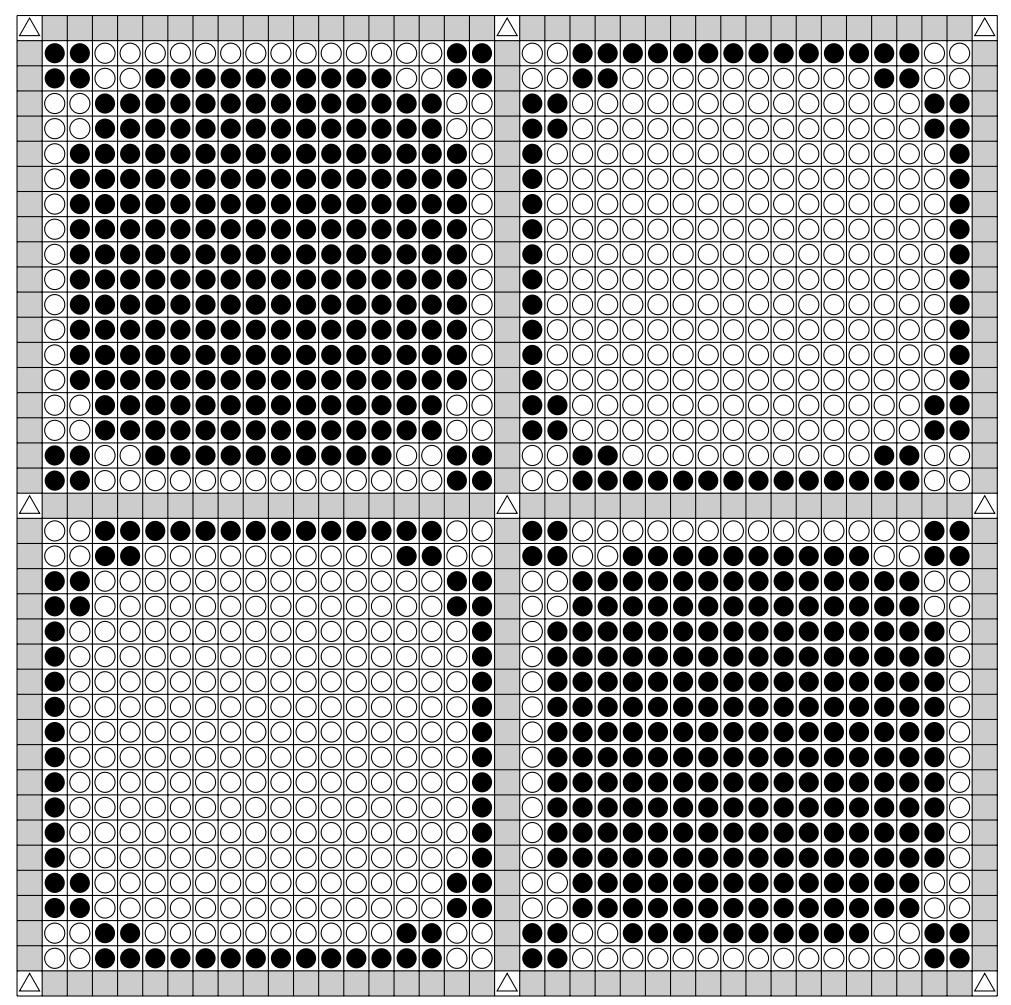

Figure 6. Corridor. 


\section{Lemma 1. Figure 6 is dead-locked.}

Proof. We show that if WHITE releases (i.e., moves) any man dead-locked in Figure 6, he loses immediately. By symmetry, we cover only a few cases. Suppose WHITE releases a wall's $\bigcirc$ in Figure 7 and captures a single $\bullet$ as Figure 8. A neighbor $\bullet$ intrudes into the cracked square (i.e., the places becoming empty by custodian capture) in Figure 9 and recaptures more than five $O$ in Figure 10. BLACK wins by R.5. If WHITE releases a corner's piece horizontally, he must soon lose by Figures 11-14; Figures 15-18 prove the vertical displacement case.

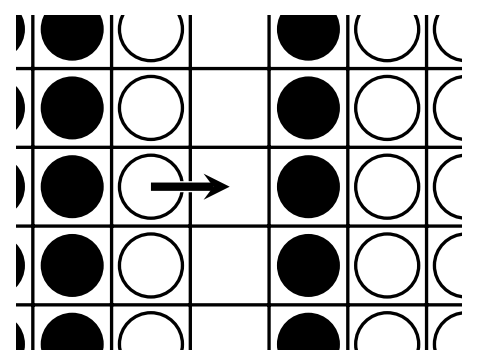

Figure 7. Wall's WHITE moves.

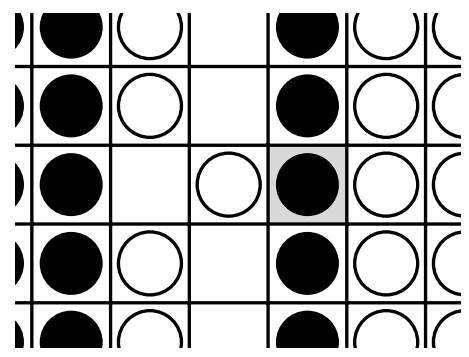

Figure 8. WHITE captures.

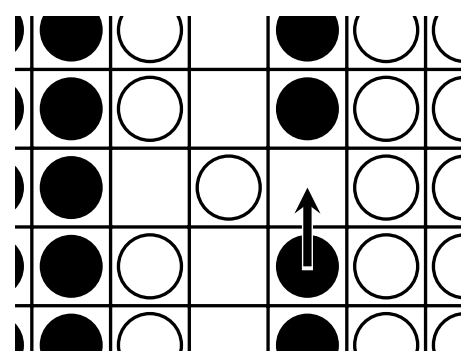

Figure 9. BLACK intrudes.

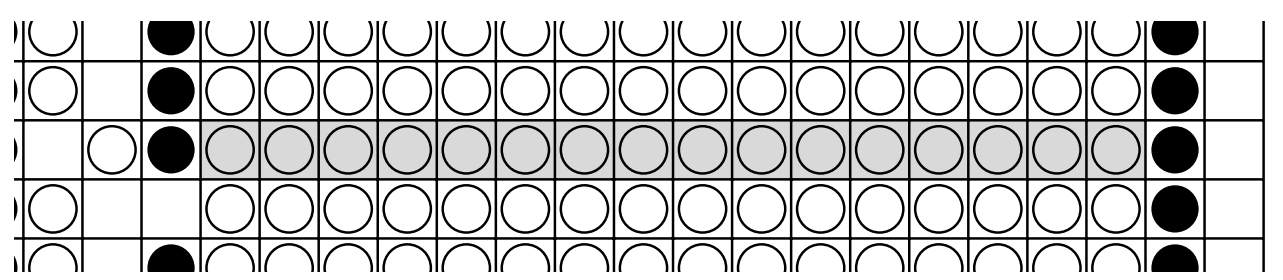

Figure 10. BLACK wins. 


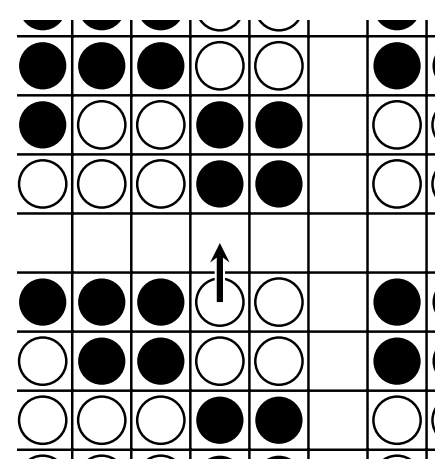

Figure 11. Corner's WHITE moves horizontally.

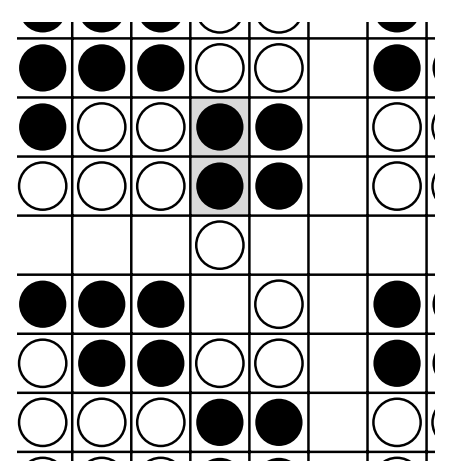

Figure 12. WHITE captures.

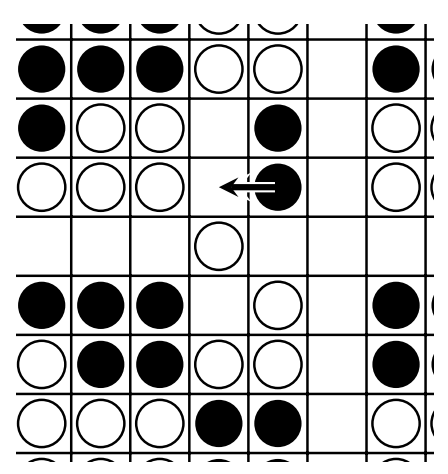

Figure 13. BLACK intrudes.

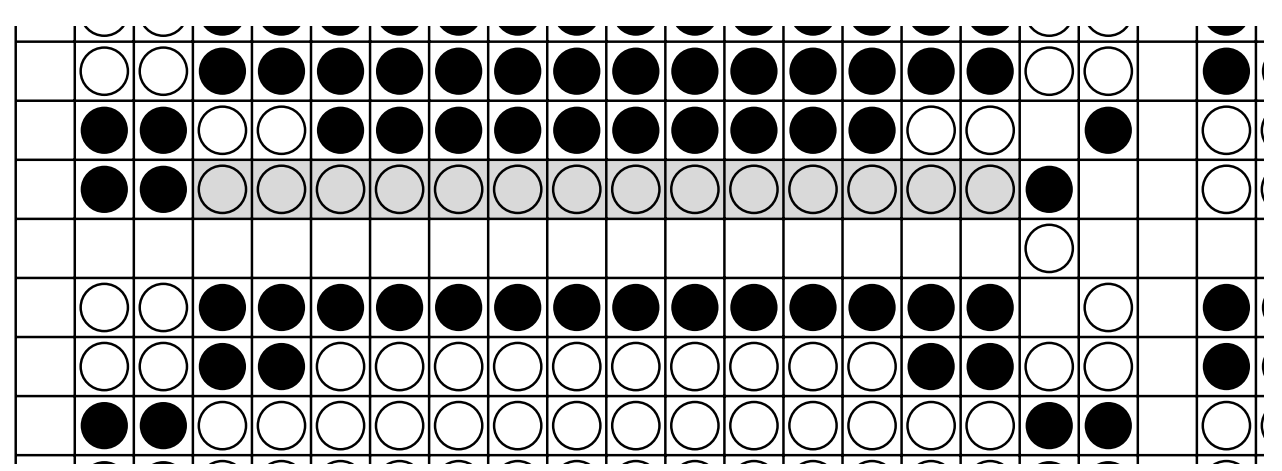

Figure 14. BLACK wins. 


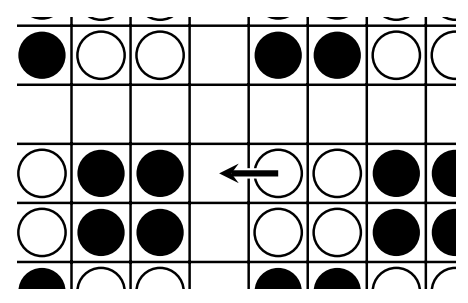

Figure 15. Corner's WHITE moves vertically.

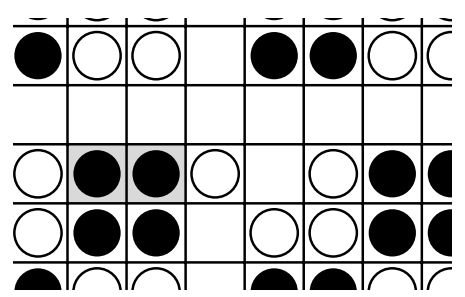

Figure 16. WHITE captures.

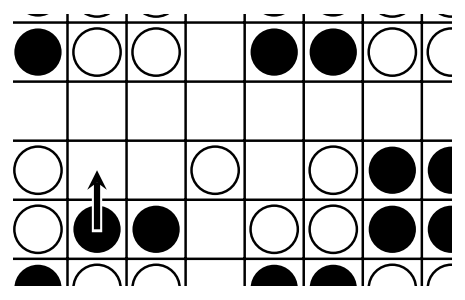

Figure 17. BLACK intrudes.

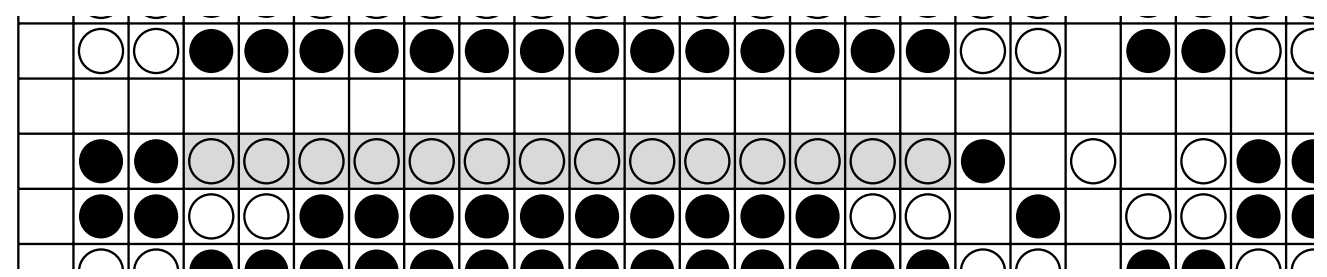

Figure 18. BLACK wins.

Figure 6 locates stoppable squares over the crossings $\Delta$, called stops. The free men can move along the passages freely but must halt at only these stops.

Lemma 2. Figure 6 forces the free men to rest at only the stops.

Proof. If the free $O$ rests at any non-stop in Figure 19 and captures a single - as Figure 20, - intrudes into the cracked square in Figure 21, recaptures more than five $O$ in Figure 22, and wins. It is the same for the non-stoppable places near corners inside the focuses B and C, as shown in Figures 11-18.

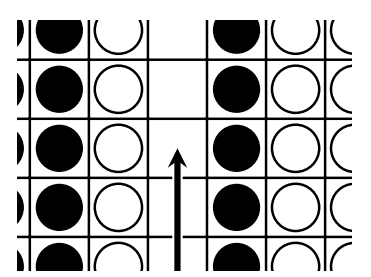

Figure 19. WHITE stops. 


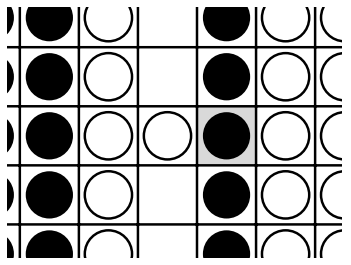

Figure 20. WHITE captures.

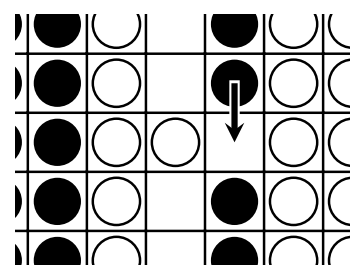

Figure 21. BLACK intrudes.

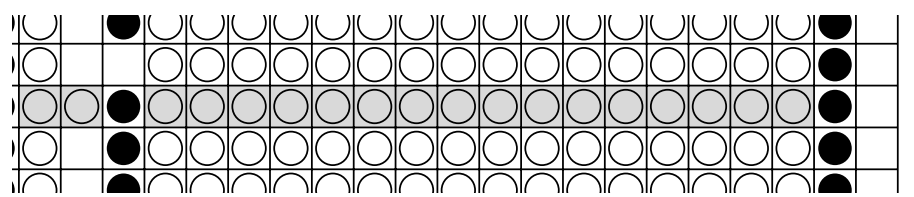

Figure 22. BLACK wins.

\subsection{Obstacles}

The corridor may give too much freedom to play any meaningful game. Figure 23 modifies it to block the passages. We call this new gadget an obstacle and abbreviate it in Figure 24. It can pave straight and L-bend routes in Figures 25 and 26.

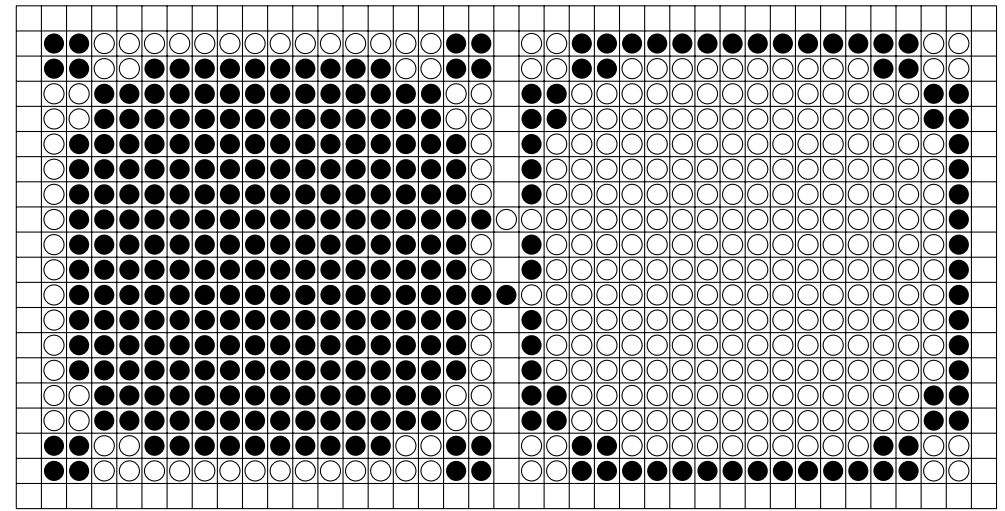

Figure 23. An obstacle.

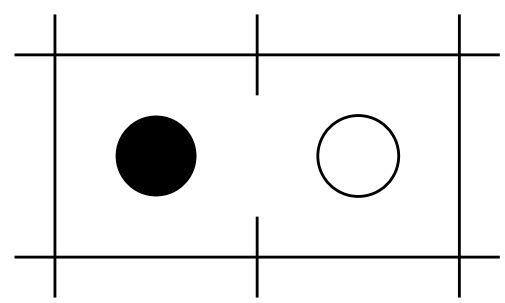

Figure 24. An obstacle, abbrev.

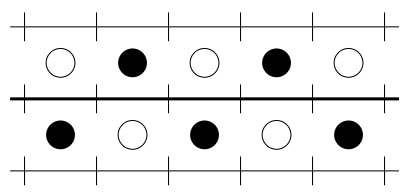

Figure 25. Straight road. 


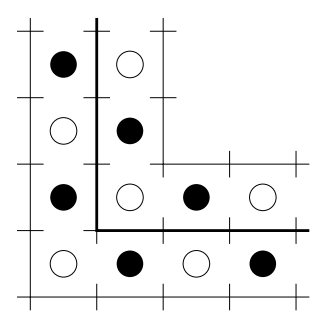

Figure 26. L-bend road.

Lemma 3. Figure 23 is dead-locked.

Proof. If WHITE releases the obstacle's $\mathrm{O}$ in Figure 27, $\bullet$ comes into the abandoned square (i.e., the place becoming empty by a man's departure from there) in Figure 28 and wins by capturing many $\bullet$ in Figure 29.

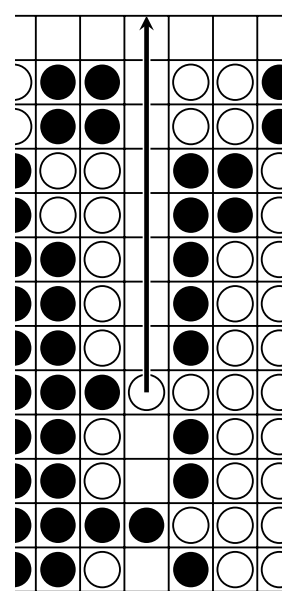

Figure 27. Obstacle's WHITE leaves.

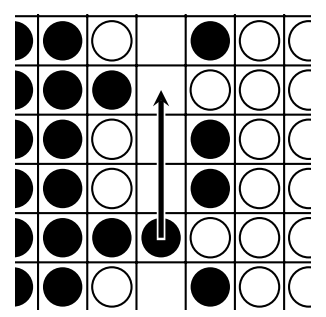

Figure 28. BLACK comes in.

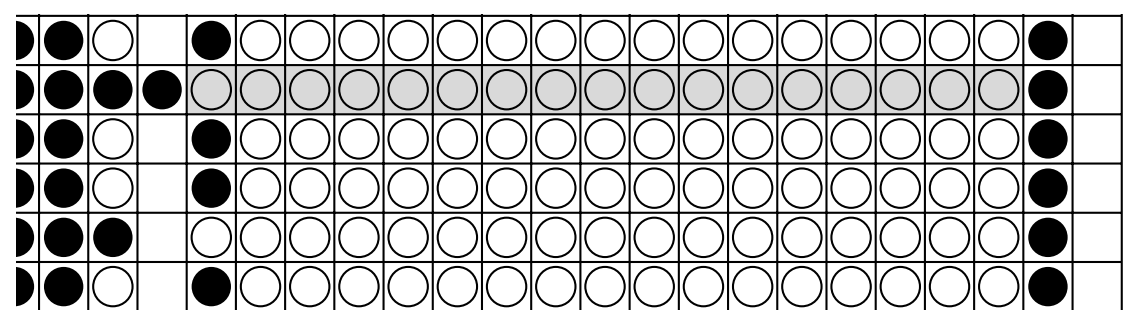

Figure 29. BLACK wins.

\subsection{One-Sided Parking Squares}

Figure 30 provides parking squares (displayed by $\mathbf{n}$ ) at which BLACK can stop but WHITE cannot. We call them B-parking squares, abbreviate it, and the dual in Figures 31 and 32 . 


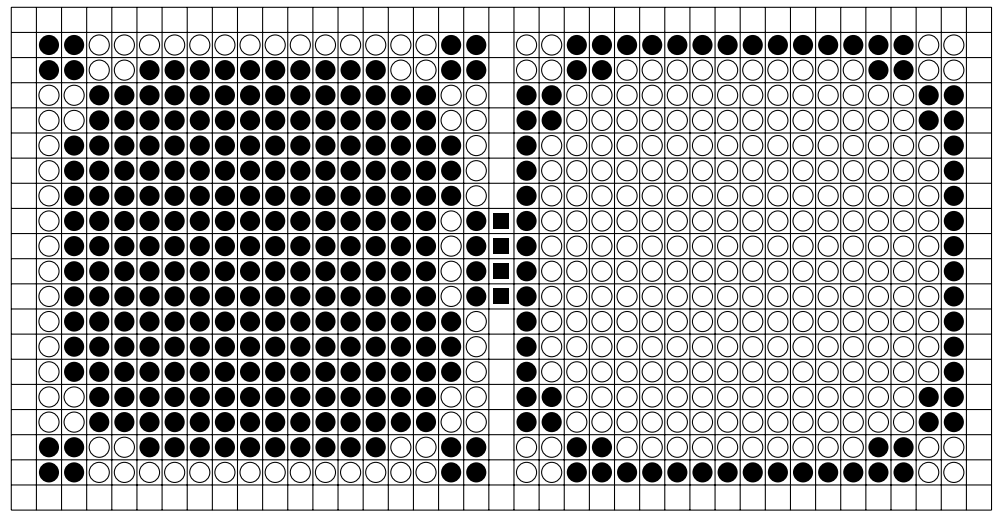

Figure 30. W-parking.

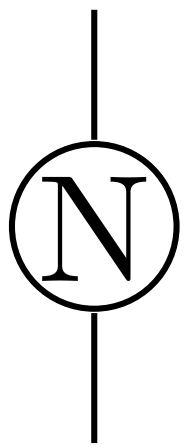

Figure 31. W-Parking, abbrev.

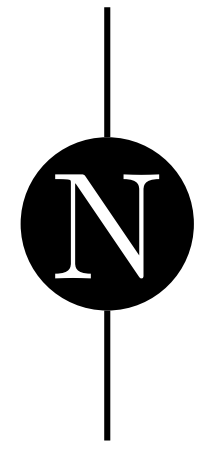

Figure 32. B-Parking, abbrev.

Lemma 4. Figure 30 is dead-locked.

Proof. If BLACK releases a left wall's man in Figure 33, $\bigcirc$ comes into the abandoned square in Figure 34 and wins by capturing five 0 in Figure 35.

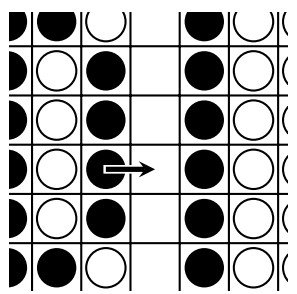

Figure 33. Parking wall's BLACK leaves. 


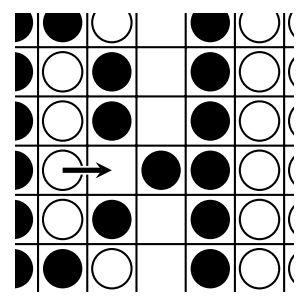

Figure 34. WHITE comes in.

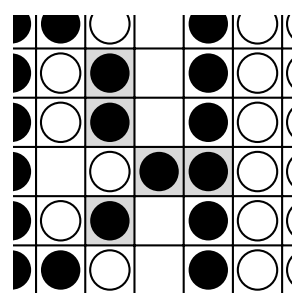

Figure 35. WHITE wins.

Lemma 5. Figure 30 forbids the free $O$ to rest at any B-parking square.

Proof. If the free $\$ w h$ rests at a B-parking square in Figure 36 and captures two $\bullet$ in Figure 37, - intrudes into the cracked yard, recaptures many $O$, and wins in Figures 38 and 39.

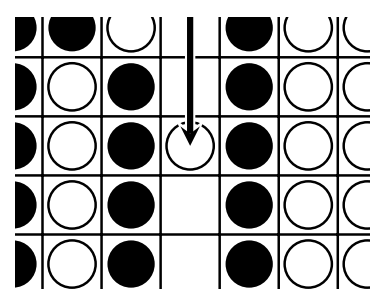

Figure 36. WHITE stops.

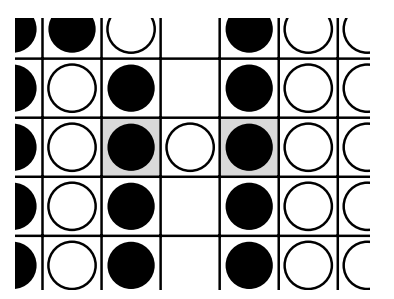

Figure 37. WHITE captures.

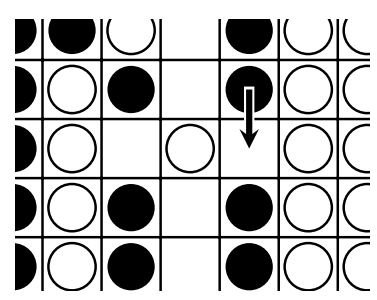

Figure 38. BLACK intrudes.

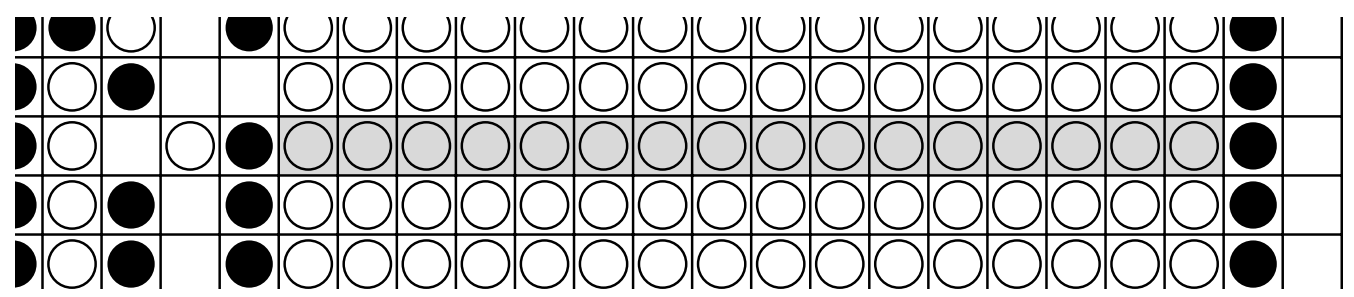

Figure 39. BLACK wins. 


\subsection{Weak Points}

Obstacles and one-sided parking squares in the previous sections explicitly bound the playing field on the gameboard. On the other hand, $\tau$-weak ones, $\tau$-timers, and $\tau$-magnets in the succeeding ones induce invisible forces bounding the player $\tau^{\prime}$ s move. Figure 40 is a $B$-weak point, modifying Figure 6 inside the focus. It contains a checkmate square $\odot$. WHITE "checkmates" if he goes there in his turn. We abbreviate it and the dual as in Figures 41 and 42.

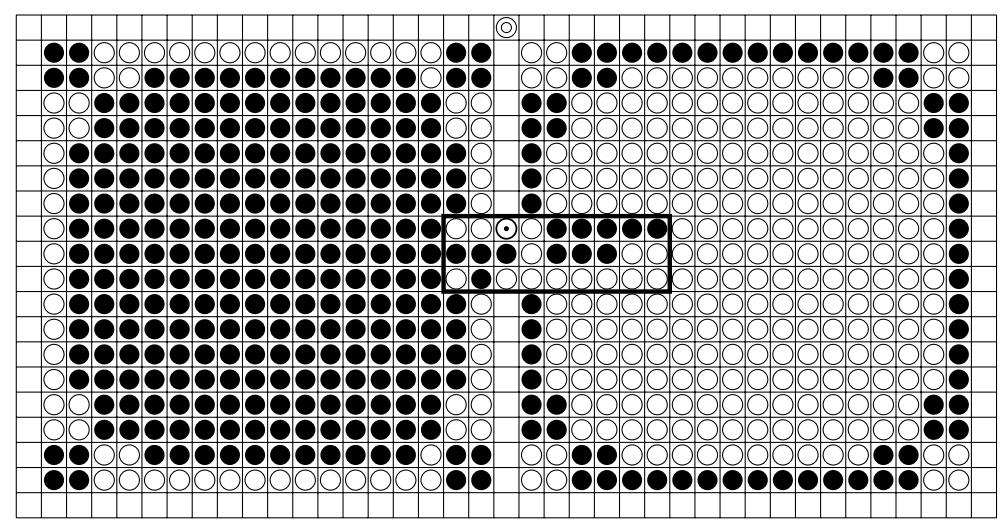

Figure 40. B-weak point with a focus.

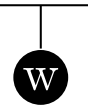

Figure 41. B-weak point, abbrev.

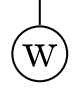

Figure 42. W-weak point, abbrev.

Lemma 6. Figure 40 is dead-locked.

Proof. If WHITE releases the right wall's $\bigcirc$ near the checkmate in Figure 43 and captures a single in Figure 44, comes into the abandoned position in Figure 45, recaptures five $O$, and wins in Figure 46. Similarly, WHITE's releasing the left wall's man near the checkmate forces his defeat in Figures 47-50. Only these two pieces entail different proofs from those shown in the previous Lemmas. For example, moving the center $\bullet$ up by one cell to occupy $\odot$ forces BLACK's defeat in several ways, say (the duals of) Figures 8-10 for the corridor, and Figures 27-29 for the obstacle.

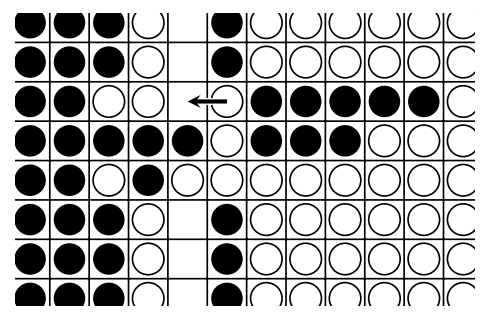

Figure 43. The center right WHITE moves. 


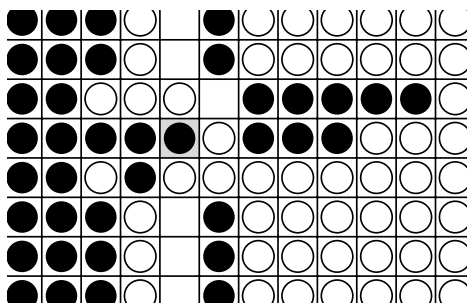

Figure 44. WHITE captures.

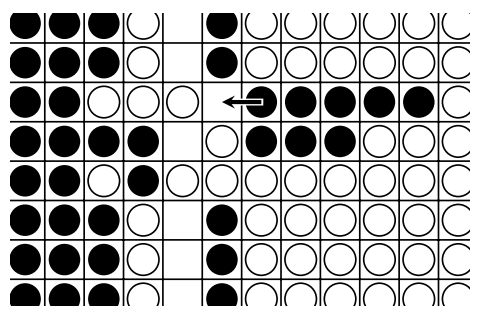

Figure 45. BLACK comes in.

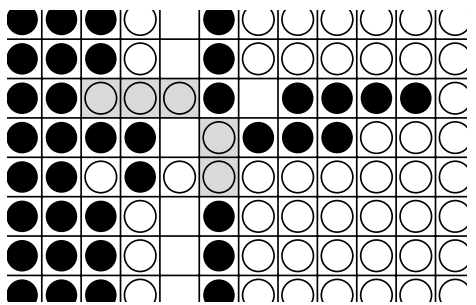

Figure 46. BLACK wins.

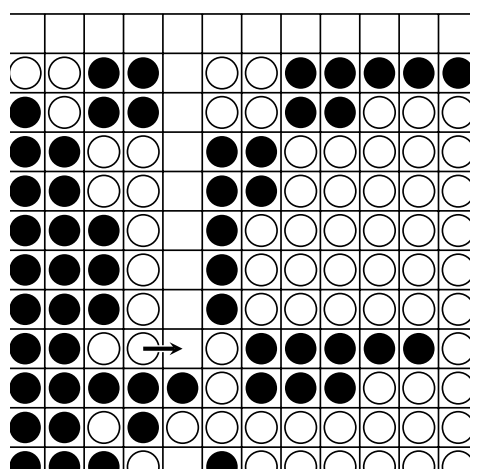

Figure 47. The center left WHITE moves.

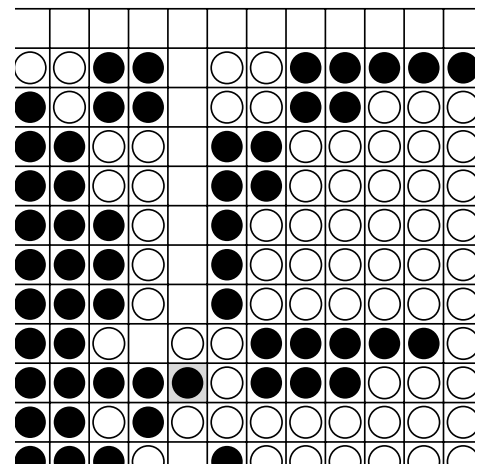

Figure 48. WHITE captures. 


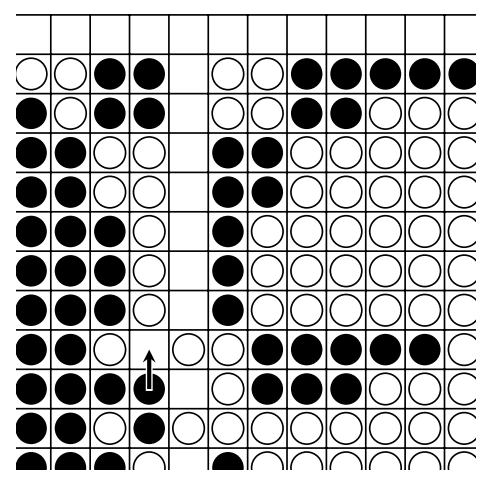

Figure 49. BLACK comes in.

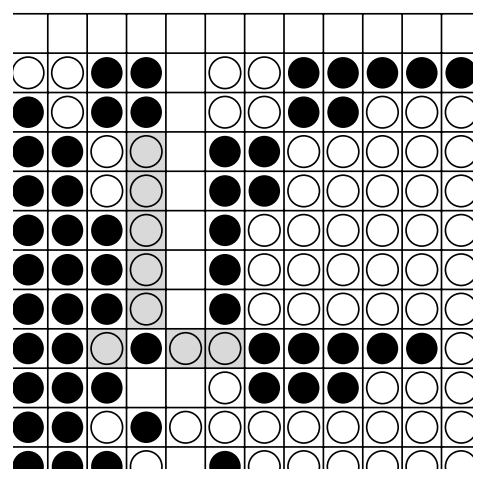

Figure 50. BLACK wins.

Lemma 7. If WHITE checkmates in Figure 40, he wins.

Proof. If WHITE checkmates in Figure 51, WHITE captures one $\bullet$ in Figure 52. In the next turn, if $\bullet$ does not intrude into the cracked place, $O$ will do it and win. Even if $\bullet$ does it and recaptures one $\mathrm{O}$ in Figures 53 and 54, $\mathrm{O}$ comes into the abandoned square in his second turn, takes many $\bullet$, and wins in Figures 55 and 56.

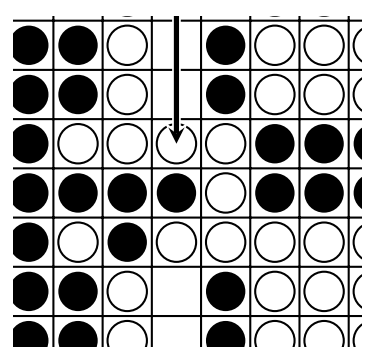

Figure 51. WHITE checkmates.

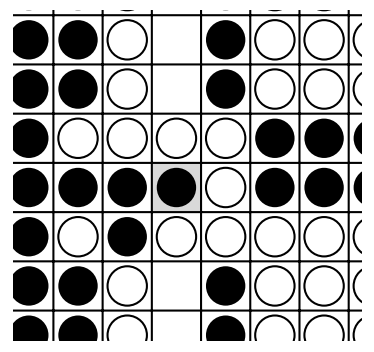

Figure 52. WHITE captures. 


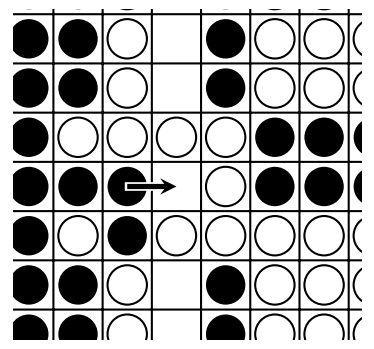

Figure 53. BLACK intrudes.

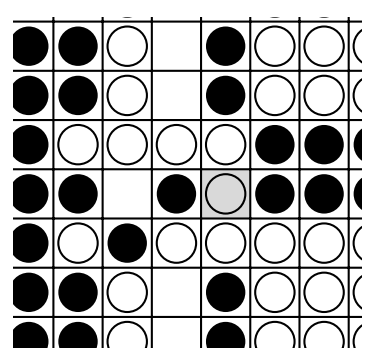

Figure 54. BLACK recaptures.

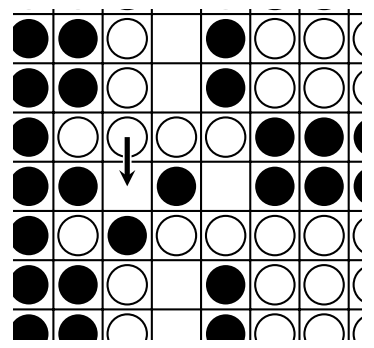

Figure 55. WHITE's second turn.

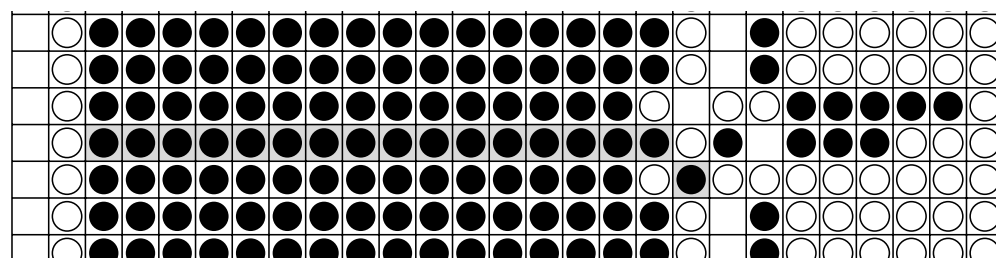

Figure 56. WHITE wins.

Notice that BLACK's invasion of the checkmating square forces his defeat shown in Figures 57-60.

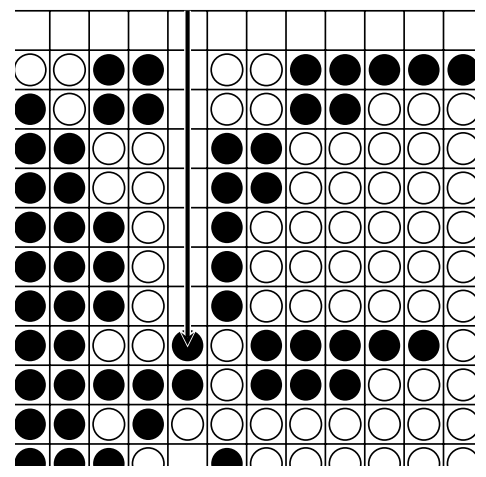

Figure 57. BLACK invades. 


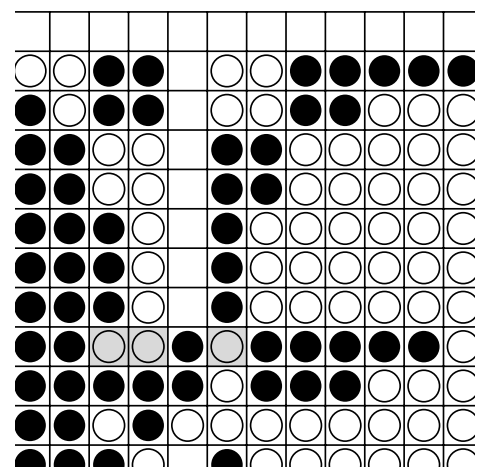

Figure 58. BLACK captures.

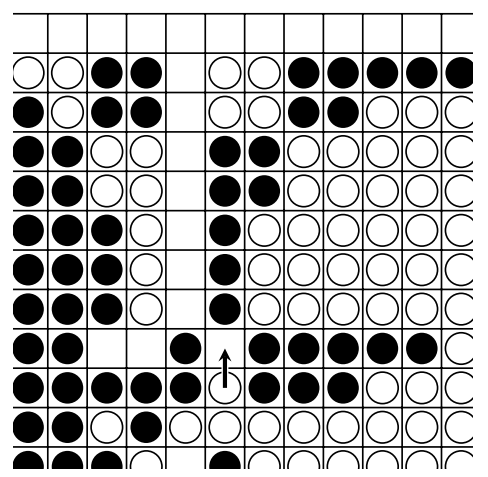

Figure 59. WHITE intrudes.

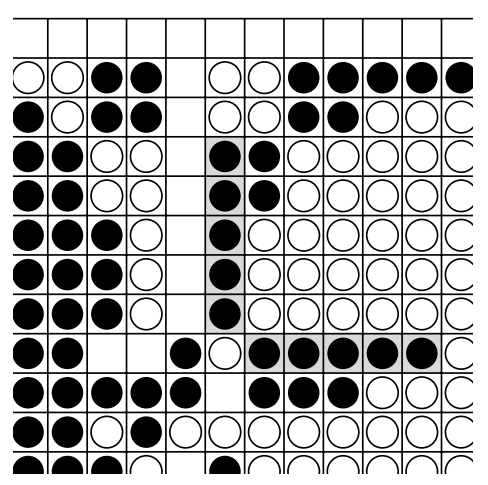

Figure 60. WHITE wins.

\subsection{Timers}

Cooperating with $\mathrm{W}$-weak points, $\mathrm{B}$-timers oblige the players to engage in the escapeand-chase game forcing the free $\mathrm{O}$ to escape and free - to chase. A B-timer gadget, Figure 61, consists of a B-weak point in the lower half and an obstacle in the upper one. Only the top and bottom lines change from Figure 40 to add Figure 62's parking squares inside the focus. The abbreviations, Figure 63 and the dual Figure 64, write an arrow to represent a passage guiding the free $\bigcirc$ to the checkmate $\odot$ and a hatched area for a corridor conducting the free $\bullet$ to the protector $\bigcirc$. 


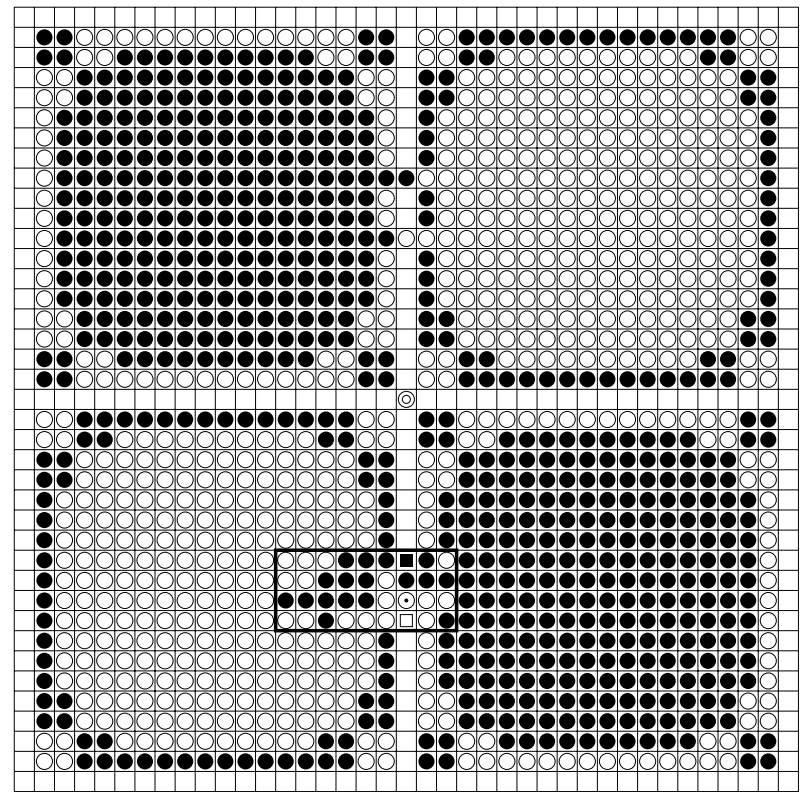

Figure 61. B-timer with a focus.

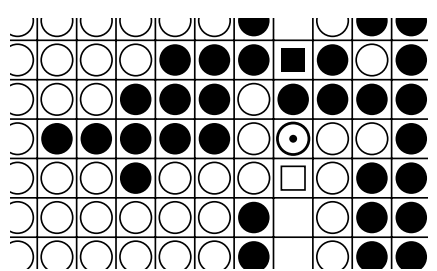

Figure 62. Parking squares.

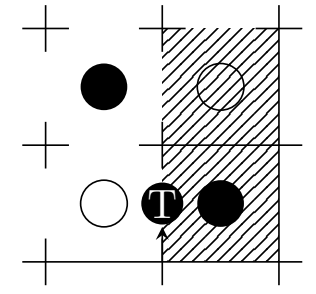

Figure 63. B-timer, abbrev.

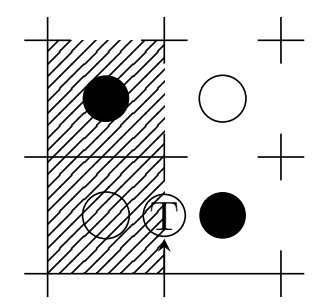

Figure 64. W-timer, abbrev.

Lemma 8. Figure 61 is dead-locked.

Proof. Lemmas 3, 4, and 6 have already shown it for the obstacle, parking squares, and weak-point gadgets, except the following case. The obstruction $O$ may invade the Bparking court in Figure 65 (see Figure 62's $\mathbf{D}$ ). It forces WHITE's defeat in several ways, e.g., Figures 27-29 for the obstacle, or Figures 66-68 for the B-parking square. 


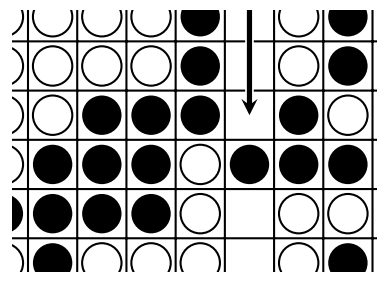

Figure 65. WHITE invades.

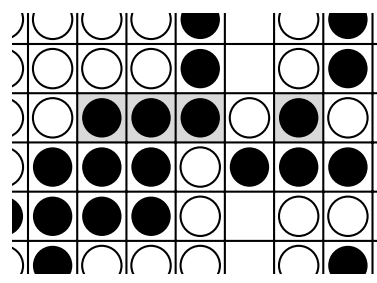

Figure 66. WHITE captures.

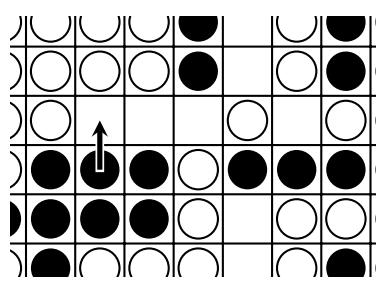

Figure 67. BLACK intrudes.

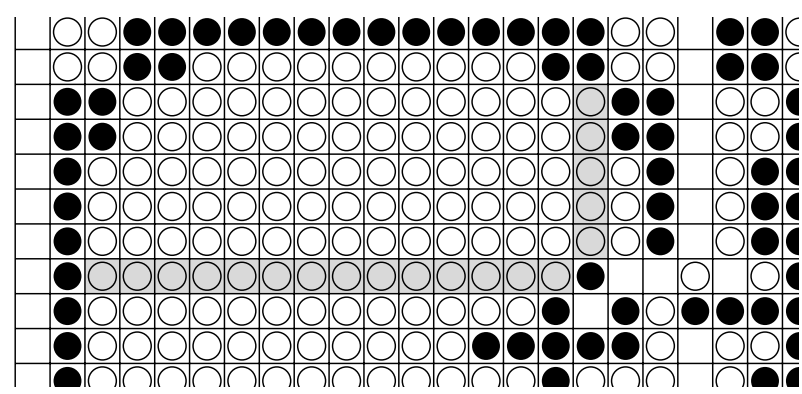

Figure 68. BLACK wins.

Lemma 9. In Figure 61, WHITE's checkmate forces BLACK's defeat unless BLACK takes the protector (i.e., moves his free man there) or captures WHITE's free man in the next turn.

Proof. If WHITE checkmates BLACK in Figure 69, BLACK must lose to WHITE's second move in Figures 70 and 71, unless BLACK strikes back as follows in the next turn: Capture the free $O$ and win as in Figures $72-74$, or take the protector and survive as in Figures 75 and 76 inside $C$.

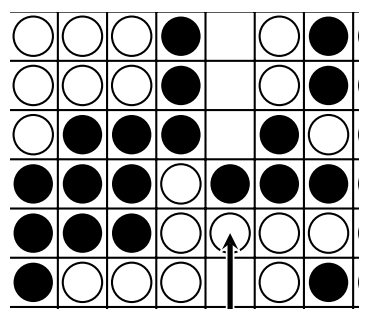

Figure 69. WHITE checkmates. 


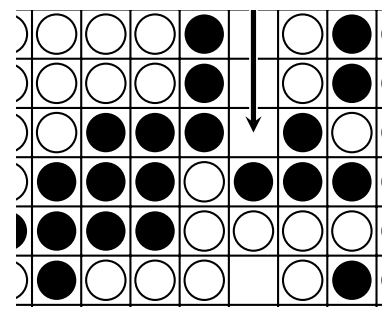

Figure 70. WHITE's second move.

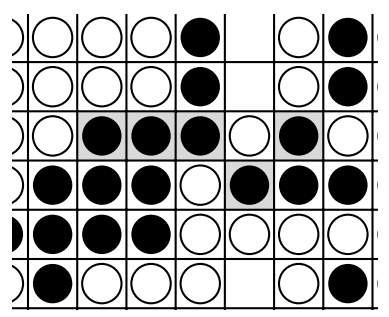

Figure 71. WHITE wins.

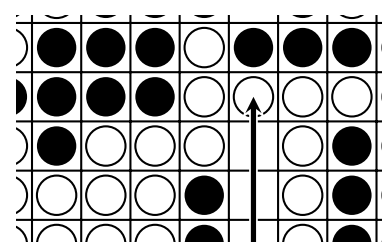

Figure 72. WHITE checkmates.

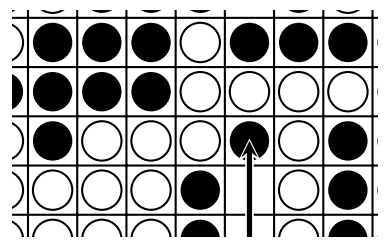

Figure 73. BLACK captures it.

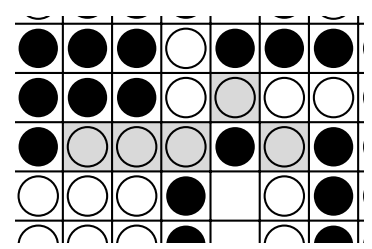

Figure 74. BLACK wins.

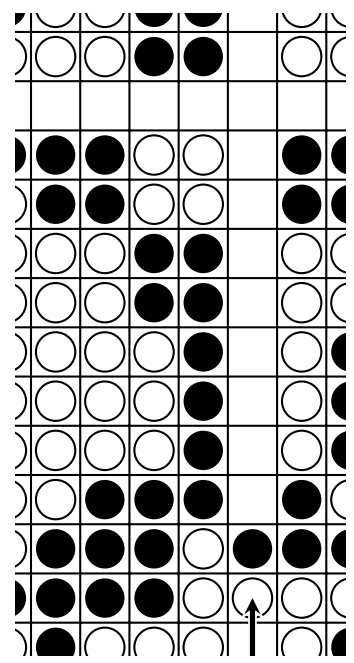

Figure 75. WHITE checkmates. 


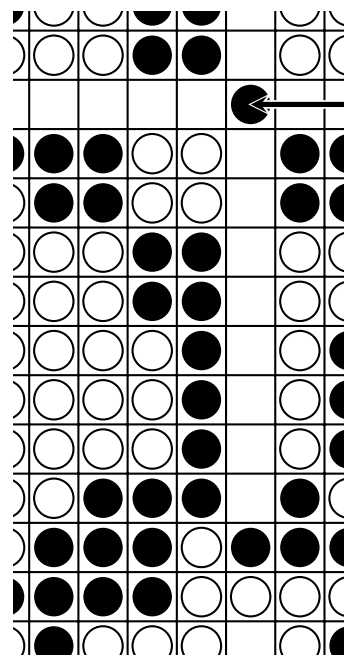

Figure 76. BLACK protects it.

BLACK's invasion of the checkmating square forces his defeat in Figures 77-80 inside the focus $B$.

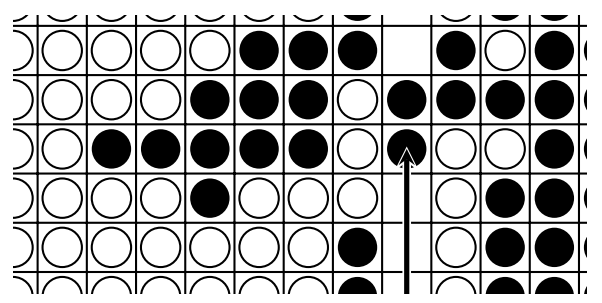

Figure 77. BLACK invades.

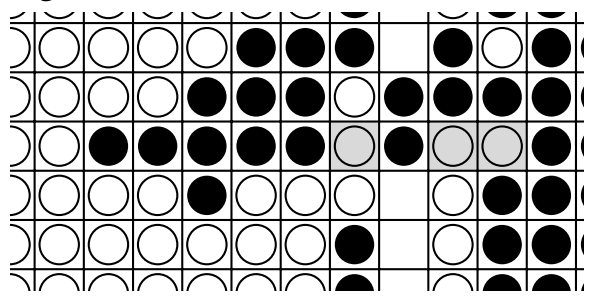

Figure 78. BLACK captures.

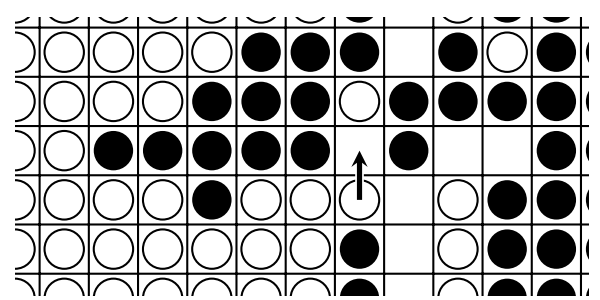

Figure 79. WHITE intrudes.

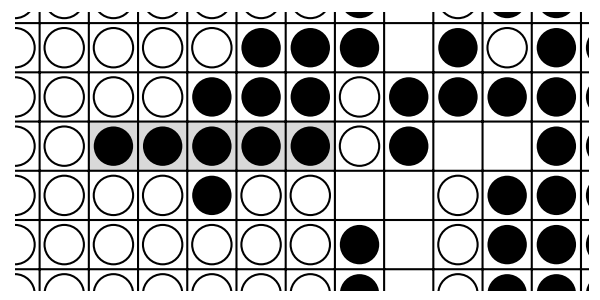

Figure 80. WHITE wins.

2.6. Magnets.

Figure 81 has the twin checkmates $\odot$, pulling the free men approaching it and finally 
catches them and bounds them staying around it. This phenomenon can make a switch gate (see Figure 105) to take only the binary states. We thus call it a W-magnet and abbreviate it and its dual in Figures 82 and 83.

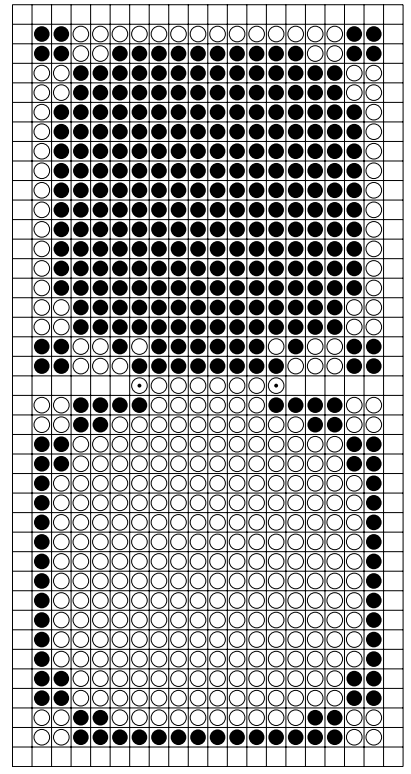

Figure 81. W-magnet.

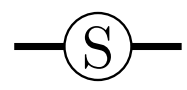

Figure 82. W-magnet, abbrev.

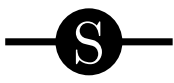

Figure 83. B-magnet, abbrev.

Lemma 10. Figure 81 is dead-locked.

Proof. If WHITE releases the center $O$ near the checkmate in Figure 84, $\bullet$ comes into the abandoned position and wins in Figures 85 and 86. If BLACK outs the upper wall's near the checkmate in Figure 87 (resp. the lower wall's one in Figure 88), O comes into there and wins in Figures 89 and 90 (resp. Figures 91 and 92). The other cases reduce to the corridor being dead-locked shown in Lemma 1.

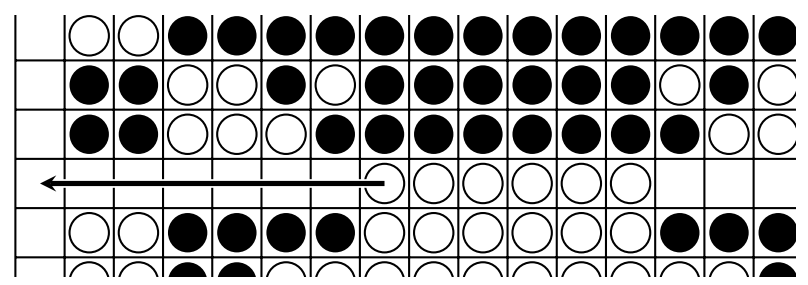

Figure 84. The center WHITE leaves.

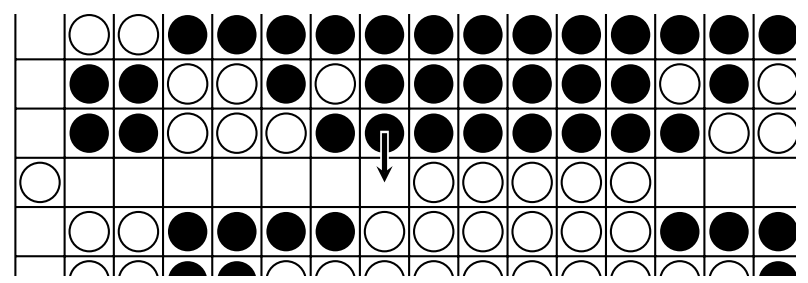

Figure 85. Black comes in. 


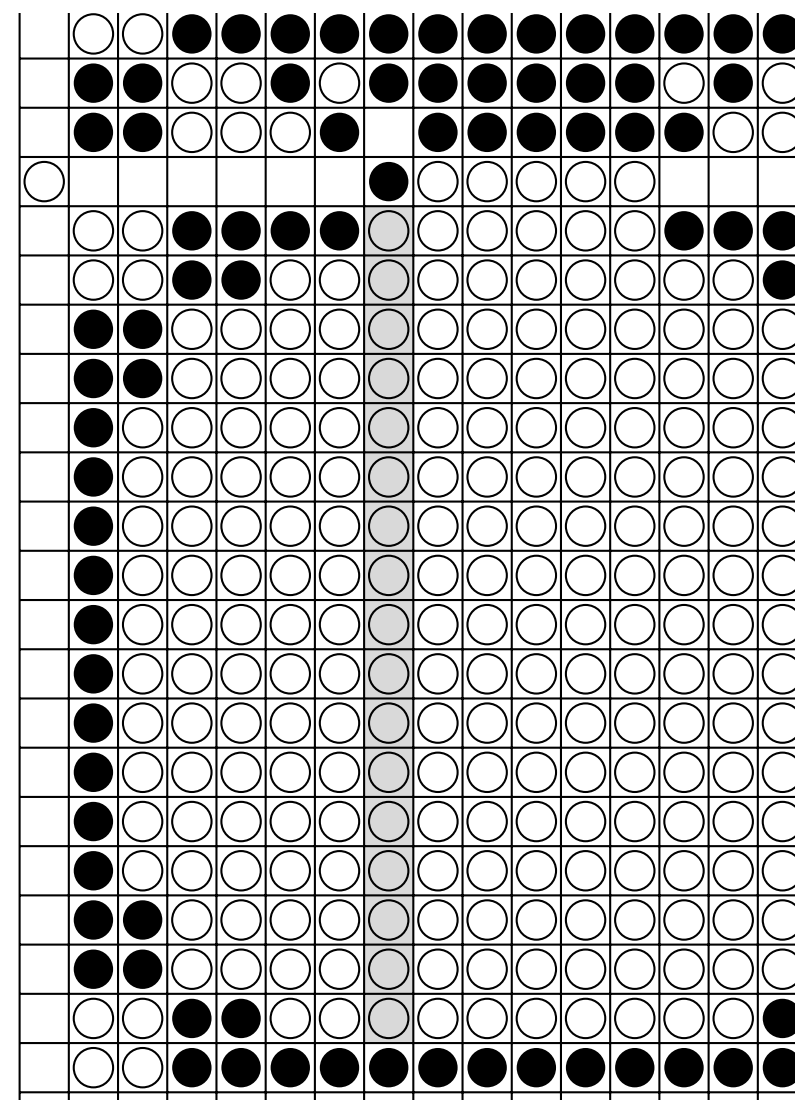

Figure 86. BLACK wins.

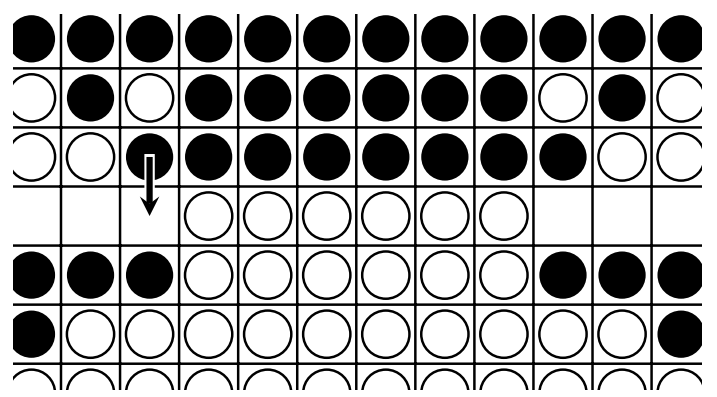

Figure 87. The upper BLACK leaves.

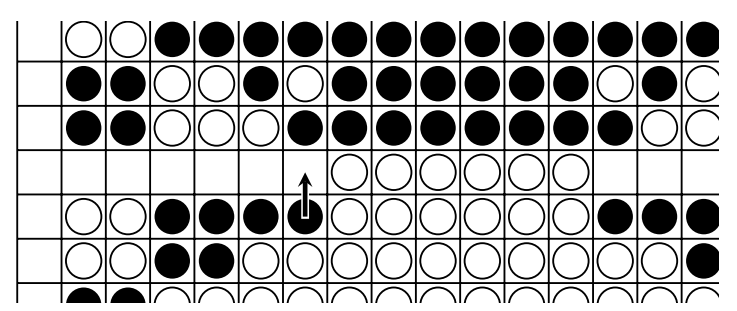

Figure 88. The lower BLACK leaves. 


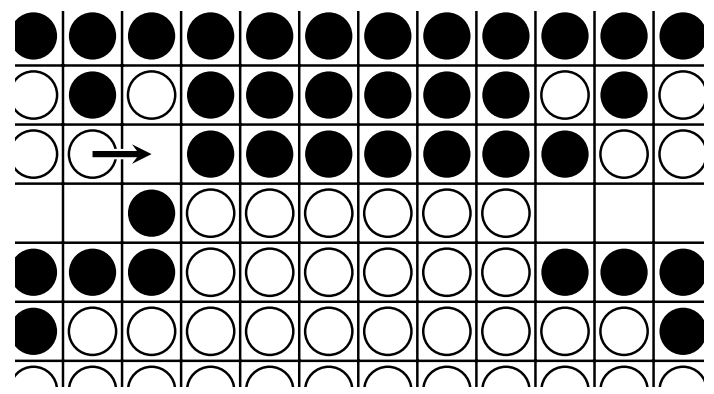

Figure 89. WHITE comes in.

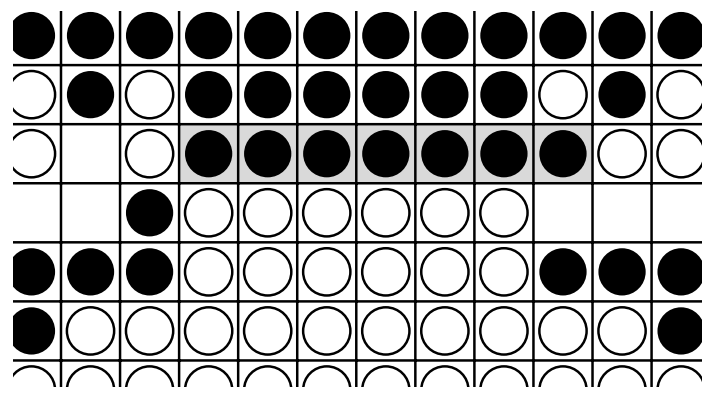

Figure 90. WHITE wins.

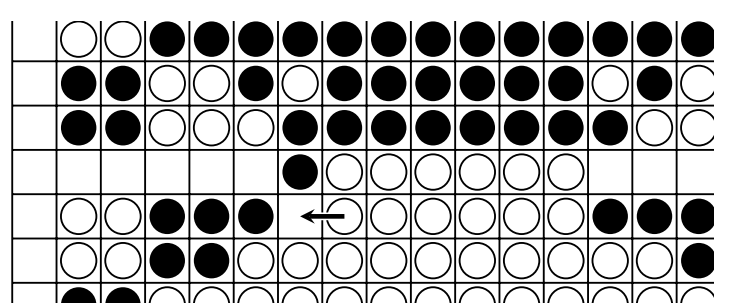

Figure 91. WHITE comes in.

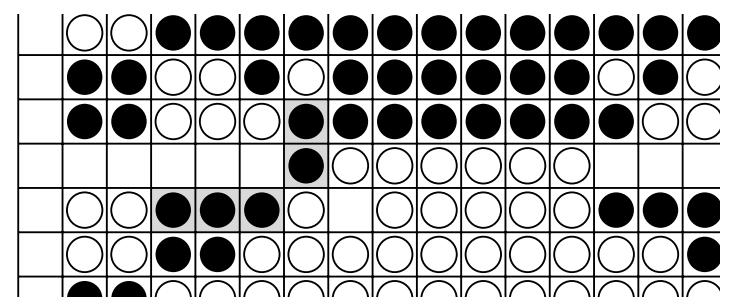

Figure 92. WHITE wins.

Lemma 11. If BLACK takes both checkmates, she wins. If WHITE takes any one of them, he loses.

Proof. BLACK takes them and wins by Figures 93 and 94. Meanwhile, if WHITE invades one of them in Figure 95 and captures two in Figure 96, BLACK intrudes into the cracked place and wins in Figures 97 and 98.

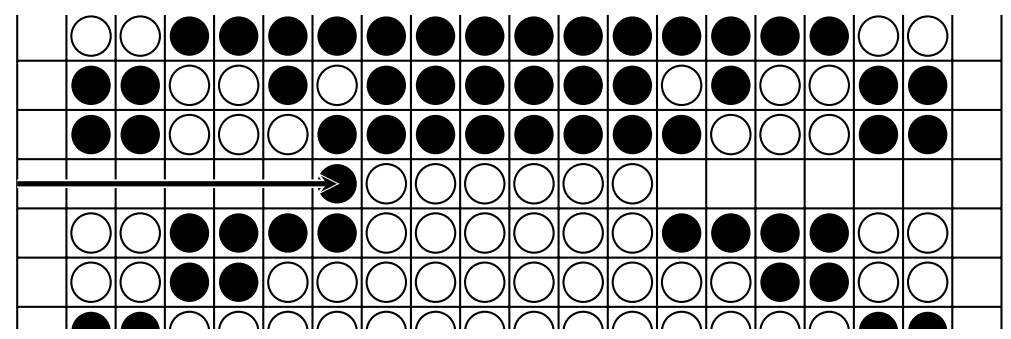

Figure 93. BLACK checkmates. 


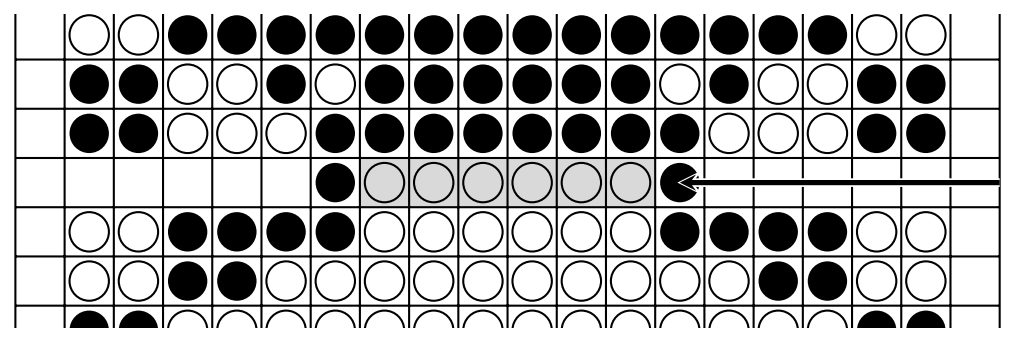

Figure 94. BLACK wins.

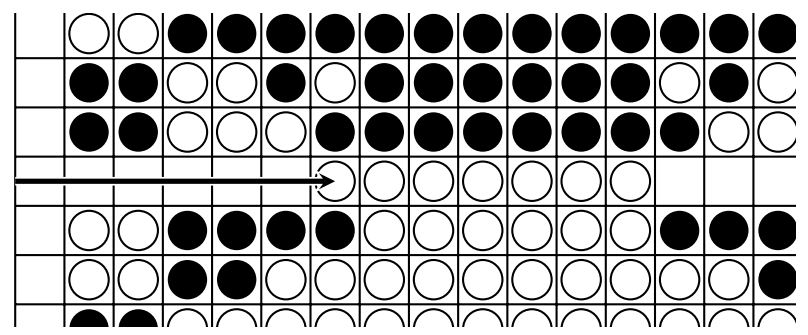

Figure 95. WHITE invades.

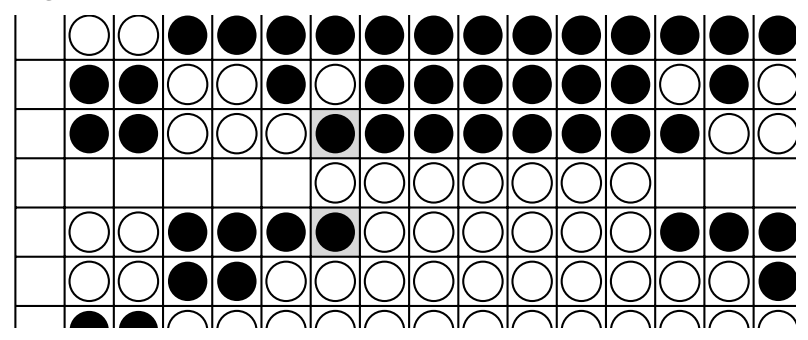

Figure 96. WHITE captures.

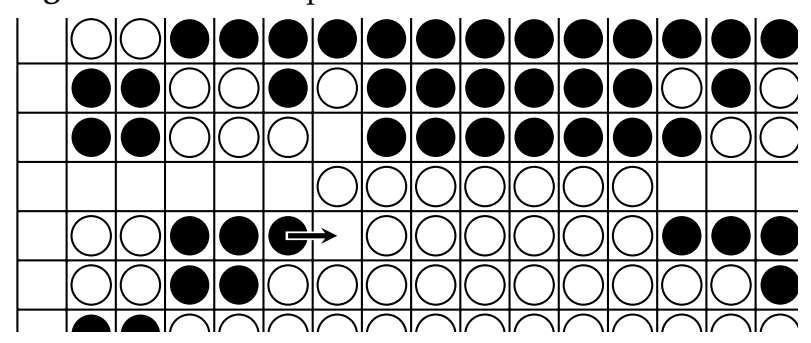

Figure 97. BLACK intrudes.

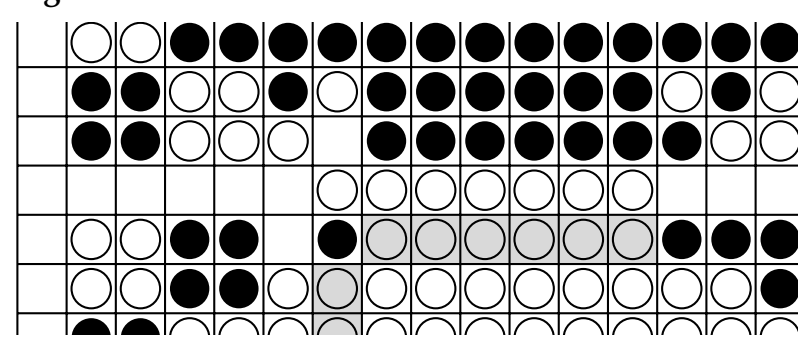

Figure 98. BLACK wins.

\section{Gates}

This section provides all gates for proving Theorem 1 . In their Figures, $\ell(A, B)$ denotes a line passing through two different points $A$ and $B, \overline{A B}$ a segment having both endpoints at $\mathrm{A}$ and $\mathrm{B}$, and $\mathrm{AB}:=\overline{\mathrm{AB}}-\{\mathrm{A}, \mathrm{B}\}$ an open piece. Each straight line in figures represents Figure 25's straight road, whose length may not represent the number of stops therein (except those lines drawing Figure 63's timer abbreviations). These geometric objects provide sets of stoppable squares (stops and parking squares), written by $|S|$ for their numbers in an object $S$, and $\tau=S$ for $\tau \in S$.

As already proved in the previous section, the players must move only their free men, so $\tau \in\{0, \bigcirc\}$ often represents the free $\tau$ and its standing square in each Figure. We write 
$(\tau, \bar{\tau})=(\mathrm{A}, \mathrm{B}) \rightarrow(\mathrm{C}, \mathrm{D})$ to say that $(\tau, \bar{\tau})=(\mathrm{A}, \mathrm{B}), \tau$ is the first to go from $\mathrm{A}$ to $\mathrm{C}$, then $\bar{\tau}$ from $B$ to $C$ in the next turn. When $\bar{\tau}$ is the first, we should write $(\bar{\tau}, \tau)=(B, A) \rightarrow(D, C)$, or $(\mathrm{A}, \mathrm{B}) \rightarrow(\mathrm{A}, \mathrm{D}) \rightarrow(\mathrm{C}, \mathrm{D})$. If it takes several turns, write $(\tau, \bar{\tau})=(\mathrm{A}, \mathrm{B}) \stackrel{*}{\rightarrow}(\mathrm{C}, \mathrm{D})$.

The checkmate squares $\odot$ in weak-points, timers, and magnets are the only places where the players can force a win. We refer to these $\odot$ by their gadget's names and measure the distance (i.e., minimum steps) $d_{\tau}(\mathrm{A}, \mathrm{G})$ for $\tau$ at $\mathrm{A}$ to reach $\mathrm{G}$ 's checkmate. Let $b_{\tau} \in\{0,1\}$ be the indicator that $\tau$ is the first to move. When the free $(\tau, \bar{\tau})=(\mathrm{A}, \mathrm{B})$, the free $\bar{\tau}$ must take one of the following three strategies against $\tau^{\prime}$ s checkmate at G. Protect $\mathrm{G}$ by $d_{\bar{\tau}}\left(\mathrm{B}, \mathrm{G}^{\prime}\right.$ s protector $) \leq d_{\tau}(\mathrm{A}, \mathrm{G}) ;$ Block $\mathrm{G}$ by $d_{\bar{\tau}}(\mathrm{B}, \mathrm{C})+b_{\tau} \leq d_{\tau}(\mathrm{A}, \mathrm{C})$ for a square $\mathrm{C}$ that $\tau$ must go through to reach $\mathrm{G}$; Surpass $\mathrm{G}$ by $d_{\bar{\tau}}(\mathrm{B}, \mathrm{H})+b_{\tau} \leq d_{\tau}(\mathrm{A}, \mathrm{G})$ for a $\bar{\tau}^{\prime}$ s checkmate $\mathrm{H}$. If $\bar{\tau}$ fails all of them, $\bar{\tau}$ must lose $\mathrm{G}$ and the game ( $\tau$ wins $\mathrm{G}$ and the game), else $\bar{\tau}$ survives $\mathrm{G}$.

In proving Theorem 1, winning by R.4 is hard to confirm since it must analyze the repetition (a.k.a., cycle, closed-loop) of positions as inevitable. The escape-and-chase game can reduce R.4 to an attack rule R.4: Make a winning repetition. Suppose that the escaper must take the unique winning moves. Immediately after the escaper has visited the same square twice, the chaser will do the same to make a sequence of positions visited only once except the current one twice. The chaser repeats walking the same path several times, forces the escaper first to stop at the same square thrice, and wins R.4. Aida, Crasmaru, Regan, and Watanabe [24] (ACRW) proved that any two-player strategy board game is extendable to another game with all positions possessing the unique winning move for either player. This remarkable result allows us to adopt $\widetilde{R} .4$ instead of R.4 for proving Theorem 1.

Definition 3 (unique winning moves). A two-player game with no infinite repetitions divides all possible positions to either player's winning ones. It has the unique winning moves if each has at most one winning move for either player in the following sense. If a player is the first to move at his winning one, he has only one action leading to his new winning one. If the opponent is the first to move there, all moves lead to the player's winning positions.

Definition 4 ( $\widetilde{\mathbf{R} .4})$. In a two-player board game, a game position is a pair $\pi=\left(\pi_{\tau}, \pi_{\bar{\tau}}\right)$ of $\tau^{\prime}$ s men's position $\pi_{\tau}$ and $\bar{\tau}^{\prime}$ 's one $\pi_{\bar{\tau}}$. Let $\# \pi_{\tau}$ be the number of times that $\tau^{\prime}$ s men have ever visited $\pi_{\tau}$ from the beginning of the game. Repetition is a closed sequence $\pi_{1} \rightarrow \ldots \rightarrow \pi_{k}=\pi_{1}$ of game positions induced by the players' moves. It is $\bar{\tau}^{\prime}$ s winning one if $\forall i, \# \pi_{i, \bar{\tau}} \leq \# \pi_{i, \tau}$. If a player succeeds in making his winning repetition by his move, he wins.

Lemma 12. In any two-player board game with unique winning moves, R.4 implies $\widetilde{R .4}$.

Proof. Let $\pi_{1} \rightarrow \cdots \rightarrow \pi_{k}=\pi_{1}$ be a winning repetition that $\bar{\tau}$ has succeeded in making by revisiting $\pi_{1, \bar{\tau}}: \forall i, \# \pi_{i, \bar{\tau}} \leq \# \pi_{i, \tau}$, and $\# \pi_{1, \bar{\tau}}<\# \pi_{1, \tau}$ before $\bar{\tau}$ revisits $\pi_{i, \bar{\tau}}$. If $\tau$ were a winner, $\tau^{\prime}$ s unique winning moves would force $\pi_{1} \rightarrow \cdots \rightarrow \pi_{k}=\pi_{1} \rightarrow \cdots \rightarrow \pi_{k}=$ $\pi_{1} \rightarrow \cdots \rightarrow \pi_{k}$ once $\bar{\tau}$ is willing to repeat the same walk. It certifies $\tau^{\prime}$ s defeat since $\tau$ visits $\pi_{1, \tau}$ thrice and violates $R .4$ before $\bar{\tau}$ does $\pi_{1, \bar{\tau}}$.

In the current Section 3 except Section 3.6, $\widetilde{R .4}$ applies $\pi_{i}$ to the free men's position $(O$, ), although $\pi_{i}$ must look at all men on the board. Theorem 1's proof will justify it in the last Section 4.

\subsection{One-Way Roads}

Figures 25 and 26 are straight and L-bend passages along which the free men can move in both forward and backward directions. One-way roads attach to them B-timers and $\mathrm{W}$-weak points in Figure 99 such that the players must proceed only in the forward direction. WHITE must escape on these one-way roads, and BLACK must chase by the unique alternative moves. We will describe it in Figure 99 (with marks in Figure 100). WHITE must escape along with $\mathrm{A} \rightarrow \mathrm{B} \rightarrow \mathrm{D} \rightarrow \mathrm{F}$, and BLACK must chase him with no delay. Notice that Figure 100 repeats congruently so that $\overline{\mathrm{LA}}$ and $\overline{\mathrm{FK}}$ (resp. $\overline{\mathrm{AB}}$ ) build the 
congruent gadget with that standing on $\overline{\mathrm{BD}}$ (resp. $\overline{\mathrm{DF}}$ ).

Lemma 13. Suppose $|T 1 C| \leq|K G|$. Figure 100 forces $(O, \bullet)=(B, A) \rightarrow(D, B) \rightarrow(F, D)$.

Proof. In the first turn, if $\mathrm{O}$ took $(\mathrm{B}, \mathrm{A}) \rightarrow(\mathrm{BD}, \mathrm{A})$, $\bullet$ would march $(\mathrm{BD}, \mathrm{A}) \rightarrow(\mathrm{BD}, \mathrm{G})$ and win for the following reason. It forces WHITE to keep $\bullet \ell(\mathrm{K}, \mathrm{H}) \Rightarrow \mathrm{O} \in \ell(\mathrm{T} 1, \mathrm{C})$ for surviving $\mathrm{w} 1$ by $\neg(\bullet \in \ell(\mathrm{K}, \mathrm{H}) \Rightarrow \mathrm{O} \in \ell(\mathrm{T} 1, \mathrm{C})) \Rightarrow d_{\bullet}(\bullet, w 1) \leq 2=d_{\circ}(\mathrm{O}, \mathrm{T} 1)$. During $(\mathrm{O}, \bullet) \in(\overline{\mathrm{KH}}-\{\mathrm{H}\}, \overline{\mathrm{T} 1 \mathrm{C}}-\{\mathrm{T} 1\}) \cup\{(\mathrm{T} 1, \mathrm{H})\}, \mathrm{BLACK}$ can protect $\mathrm{T} 1$ by $d_{\bullet}(\bullet, \mathrm{H})=$ $d_{\circ}(\mathrm{O}, \mathrm{T} 1) \leq 1$, exceed $\mathrm{T} 2$ by $d_{\bullet}(\bullet, \mathrm{w} 1) \leq 2<3=d_{\circ}(\mathrm{O}, \mathrm{T} 2)$, and finally gets an R.4's winning repetition $(\mathrm{C}, \mathrm{G}) \rightarrow(\mathrm{T} 1, \mathrm{H}) \rightarrow(\mathrm{C}, \mathrm{G})$. In the repetition, $\mathrm{O}$ may stop at the parking in T1 (see Figure 61's $\square$ ), but can respond it at a stop in KG on the assumption $|\mathrm{T} 1 \mathrm{C}| \leq|\mathrm{KG}|$, e.g., $(\mathrm{C}, \mathrm{G}) \rightarrow(\mathrm{T} 1, \mathrm{H}) \rightarrow(\mathrm{T} 1 \mathrm{C}, \mathrm{KG}) \rightarrow(\mathrm{C}, \mathrm{G})$.

Similarly, the congruent geometry forbids $\mathrm{O}$ at $\mathrm{B}$ to go up or down since the following are equivalent; $(\bullet, \mathrm{O})=(\mathrm{A}, \ell(\mathrm{B}, \mathrm{I})-\{\mathrm{D}\})$ in BLACK's turn forces WHITE's defeat; $(\bullet, \mathrm{O})=(\mathrm{L}, \ell(\mathrm{G}, \mathrm{A})-\{\mathrm{B}\})$ in BLACK's turn forces WHITE's defeat. Consequently, $\mathrm{O}$ must proceed $(\mathrm{B}, \mathrm{A}) \rightarrow(\mathrm{D}, \mathrm{A})$, then $\bullet:(\mathrm{D}, \mathrm{A}) \rightarrow(\mathrm{D}, \mathrm{B})$ for surviving T2 by $\in \overline{\mathrm{GA}}-$ $\{\mathrm{B}\} \Rightarrow d_{\circ}(\mathrm{D}, \mathrm{T} 2)=2 \leq d_{\bullet}(\bullet, \mathrm{w} 1) \leq 3=d_{\bullet}(\bullet, J)$. The same argument brings $(\mathrm{D}, \mathrm{B}) \rightarrow$ $(\mathrm{F}, \mathrm{D})$ in the second turn since $\overline{\mathrm{AB}} \cup \overline{\mathrm{BD}} \cup \overline{\mathrm{DF}}$ and $\overline{\mathrm{BD}} \cup \overline{\mathrm{DF}} \cup \overline{\mathrm{FK}}$ are congruent.

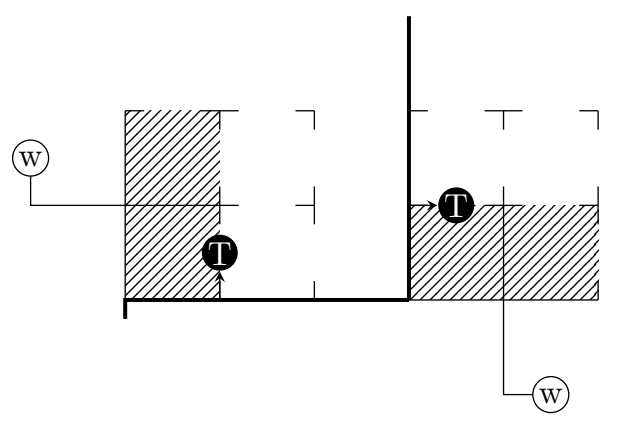

Figure 99. One-way road.

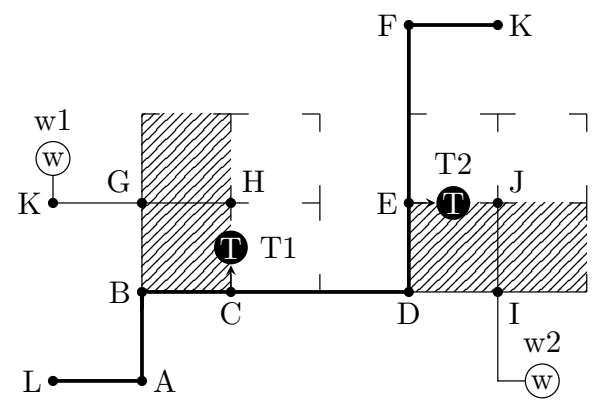

Figure 100. One-way road with marks.

\subsection{Bridges}

A bridge stands over a crossing point of two one-way roads prohibiting the players from changing their directions; they must go straight and never to the left or right. Figure 101 draws a bridge. The players coming from the left (resp. down) must go to the right (resp. up) direction.

Lemma 14. Suppose $|F T 1| \leq \mid$ LO|. Figure 101 forces $(O, \bullet)=(B, A) \rightarrow(C, K) \rightarrow(F, L) \rightarrow$ $(I, H) \rightarrow(V, I)$ or $(B, A) \rightarrow(C, K) \rightarrow(F, L) \rightarrow(T 1, O) \rightarrow(G, P) \rightarrow(I, H) \rightarrow(V, I)$.

Proof. Similar to Lemma 13's proof. In the first turn, $\mathrm{O}$ must proceed $(\mathrm{B}, \mathrm{A}) \rightarrow(\mathrm{C}, \mathrm{A})$ for surviving $\mathrm{w} 1$ by $\mathrm{O} \notin \ell(\mathrm{C}, \mathrm{F}) \Rightarrow d_{\bullet}(\mathrm{A}, \mathrm{w} 1)=d_{\circ}(\mathrm{O}, \mathrm{T} 1)=3$; Lemma 13 showed $\mathrm{O}$ could never win the timer on BC. Similarly, $\bullet:(C, A) \rightarrow(C, K)$ for surviving T1 by - $\notin \ell(\mathrm{L}, \mathrm{R}) \Rightarrow d_{\circ}(\mathrm{C}, \mathrm{T} 1)=2<3=d_{\bullet}(\bullet, \mathrm{w} 1)=d_{\bullet}(\bullet, \mathrm{O})$. Similarly, $(\mathrm{C}, \mathrm{K}) \rightarrow(\mathrm{F}, \mathrm{L})$ in the second turn. 
In the third turn, $\mathrm{O}$ cannot go backward unless losing $\mathrm{w} 1$ as above. The $\mathrm{O}$ may stick to FT1 to checkmate at T1, but - can wait for it in $\mathrm{LO}$ on the assumption $|\mathrm{FT} 1| \leq|\mathrm{LO}|$ and keep protecting $\mathrm{T} 1$ by $d_{\bullet}(\mathrm{LO}, \mathrm{O})=d_{\circ}(\mathrm{FT} 1, \mathrm{~T} 1)=1$.

In more concrete terms, during $(\mathrm{O}, \bullet) \in \mathrm{FT} 1 \times \mathrm{LO}$, the men can take each stop at most once, e.g., if $\{\mathrm{X} 1, \mathrm{X} 2\} \subset \mathrm{FT} 1,\{\mathrm{Y} 1, \mathrm{Y} 2\} \subset \mathrm{LO}$, and $\mathrm{O}$ took $\mathrm{X} 1$ twice by $(\mathrm{F}, \mathrm{L}) \rightarrow(\mathrm{X} 1, \mathrm{Y} 1) \rightarrow$ $(\mathrm{X} 2, \mathrm{Y} 2) \rightarrow(\mathrm{X} 1, \mathrm{Y} 2)$, 0 would get an $\widetilde{\mathrm{R} .4}$ 's winning repetition $(\mathrm{X} 1, \mathrm{Y} 1) \rightarrow(\mathrm{X} 2, \mathrm{Y} 2) \rightarrow$ $(\mathrm{X} 1, \mathrm{Y} 1)$. It obliges $\mathrm{O}:(\mathrm{F}, \mathrm{L}) \rightarrow(\mathrm{G}, \mathrm{L})$ or $(\mathrm{T} 1, \mathrm{~L})$ without delay. The former case forces - : $(\mathrm{G}, \mathrm{L}) \rightarrow(\mathrm{G}, \mathrm{P})$ to survive $\mathrm{T} 2$ by $\bullet \notin \ell(\mathrm{H}, \mathrm{W}) \Rightarrow d_{\circ}(\mathrm{G}, \mathrm{T} 2)=3<4=d_{\bullet}(\bullet, \mathrm{U})$. The latter case forces $\bullet:(\mathrm{F}, \mathrm{L}) \rightarrow(\mathrm{T} 1, \mathrm{O})$ for protecting $\mathrm{T} 1, \mathrm{O}:(\mathrm{T} 1, \mathrm{O}) \rightarrow(\mathrm{G}, \mathrm{O})$ by $\widetilde{\mathrm{R} .4}$, and - : $(\mathrm{G}, \mathrm{O}) \rightarrow(\mathrm{G}, \mathrm{P})$ to survive $\mathrm{T} 2$.

In the fourth turn, $O$ must go $(\mathrm{G}, \mathrm{P}) \rightarrow(\mathrm{I}, \mathrm{P})$ for surviving w3 by $\bigcirc \notin \ell(\mathrm{V}, \mathrm{I}) \Rightarrow$ $d_{\bullet}(\mathrm{P}, \mathrm{w} 3)=d_{\circ}(\mathrm{O}, \mathrm{T} 2)=3$, and $\bullet:(\mathrm{I}, \mathrm{P}) \rightarrow(\mathrm{I}, \mathrm{H})$ for surviving $\mathrm{T} 2$ by $\bullet \notin \overline{\mathrm{HW}}-\{\mathrm{H}\} \Rightarrow$ $d_{\circ}(\mathrm{I}, \mathrm{T} 2)=2 \leq d_{\bullet}(\bullet, \mathrm{w} 3) \leq 3=d_{\bullet}(\bullet, \mathrm{U})$.

Once the men reach $(\mathrm{I}, \mathrm{H})$, Lemma 13 brings $(\mathrm{O}, \boldsymbol{\bullet})=(\mathrm{I}, \mathrm{H}) \rightarrow(\mathrm{V}, \mathrm{I})$.

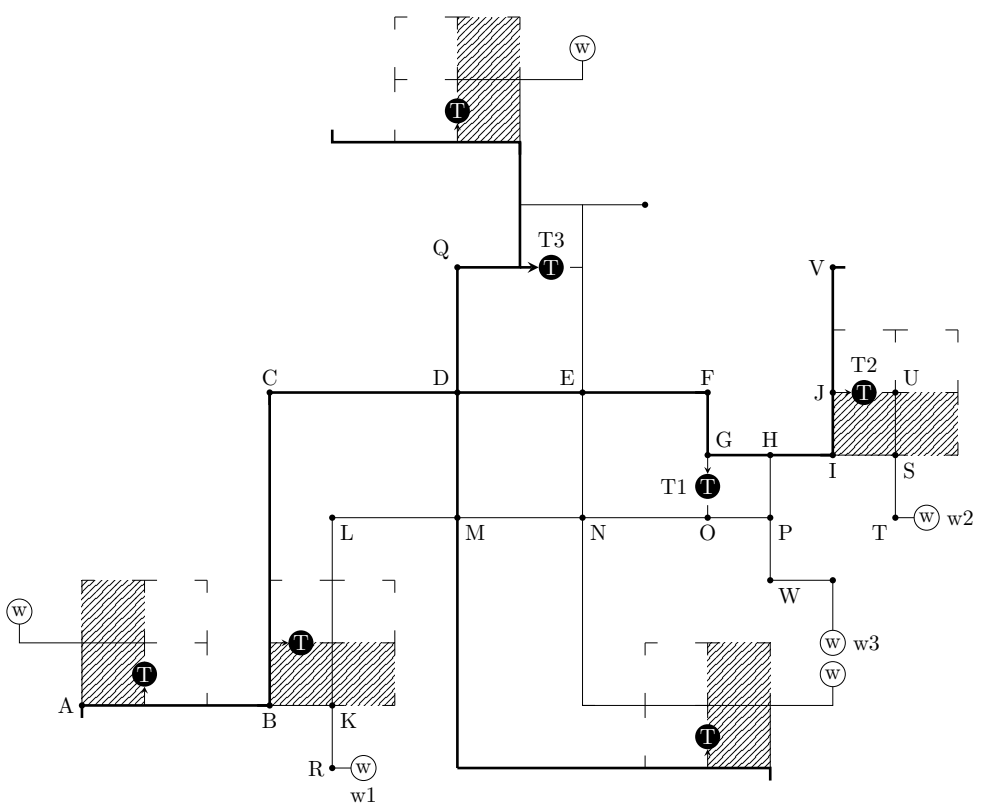

Figure 101. Bridge.

\subsection{Branches}

A branch is a T-junction where the escaper can choose the direction to proceed, to the left or right, by his choice. Figure 102 draws a W-branch, where the players coming from down must go together to either left or right by WHITE's determination of the directions.

Lemma 15. Figure 102 forces $(O, \bullet)=(B, A) \rightarrow(C, B) \rightarrow(D, C)$ (to the left) or $(B, A) \rightarrow$ $(E, B) \rightarrow(F, E)$ (to the right) by WHITE's choice.

Proof. Since both the gadgets over $\overline{\mathrm{AB}} \cup \overline{\mathrm{BC}} \cup \overline{\mathrm{CD}}$ and $\overline{\mathrm{AB}} \cup \overline{\mathrm{BE}} \cup \overline{\mathrm{EF}}$ are the one-way roads congruent with that over Figure 100's $\overline{\mathrm{AB}} \cup \overline{\mathrm{BD}} \cup \overline{\mathrm{DF}}$, Lemma 13 obliges the free $\mathrm{O}$ at $\mathrm{B}$ to choose $(\mathrm{B}, \mathrm{A}) \rightarrow(\mathrm{C}, \mathrm{B})$ or $(\mathrm{E}, \mathrm{B})$ to proceed, whichever induces the claimed subsequent moves. 


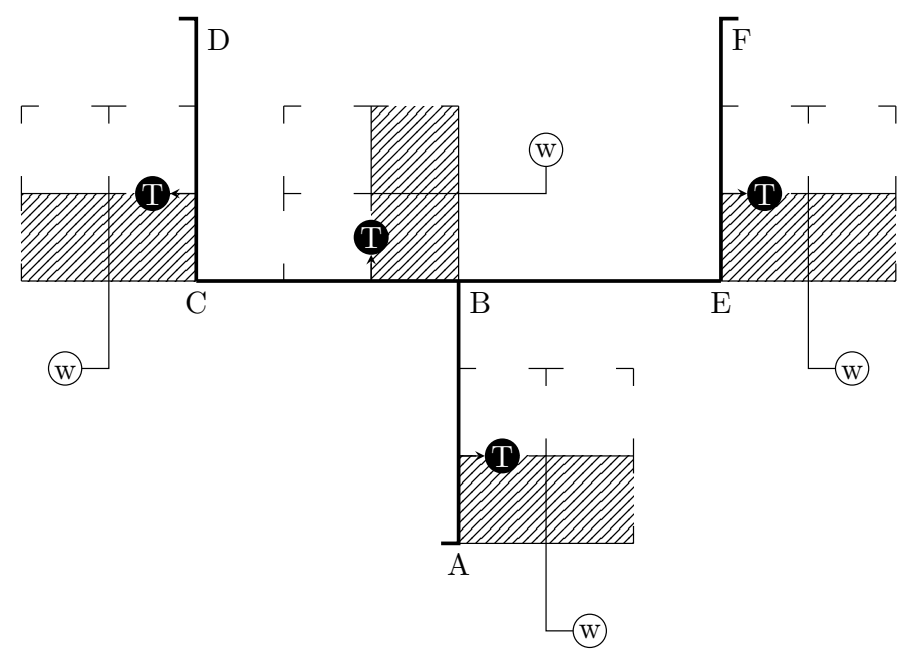

Figure 102. W-branch.

\subsection{Junctions}

Junctions gather the one-way roads multiplied by branches into one. Figure 103 builds it such that the players coming together from either the left or right must go in the upward direction.

Lemma 16. Suppose $|N G| \geq 1$. Figure 103 forces $(O, \bullet)=(B, A) \rightarrow(D, B) \rightarrow(F, D) \rightarrow$ $(Q, F)$ (from the left) and $(O, \bullet)=(I, H) \rightarrow(L, I) \rightarrow(F, L) \rightarrow(Q, F)$ (from the right).

Proof. Similar to Lemma 13's proof. When they come from the left (B, A), $O$ must proceed $(\mathrm{B}, \mathrm{A}) \rightarrow(\mathrm{D}, \mathrm{A})$ for surviving $\mathrm{w} 1$ and $\mathrm{w} 2$ by $\mathrm{O} \notin \mathrm{BP}-\{\mathrm{B}, \mathrm{D}\} \Rightarrow d_{\bullet}(\mathrm{A}, \mathrm{w} 1)=$ $d_{\bullet}(\mathrm{A}, \mathrm{w} 2)=d_{\circ}(\mathrm{O}, \mathrm{T} 1)=d_{\circ}(\mathrm{O}, \mathrm{T} 3)=3 \leq d_{\circ}(\mathrm{O}, \mathrm{T} 4)$; Lemma 13 showed $\mathrm{O}$ could never win T2. Lemma 13 forces $\bullet:(\mathrm{D}, \mathrm{A}) \rightarrow(\mathrm{D}, \mathrm{B})$.

In the second turn, if $\mathrm{O}$ went down $(\mathrm{D}, \mathrm{B}) \rightarrow(\mathrm{L}, \mathrm{B})$, he would lose as follows. The - must respond $(\mathrm{L}, \mathrm{B}) \rightarrow(\mathrm{L}, \mathrm{G})$ for surviving T5 by $\bullet \notin \overline{\mathrm{BP}}-\{\mathrm{B}, \mathrm{G}\} \Rightarrow d_{\circ}(\mathrm{L}, \mathrm{T} 5)=$ $d_{\bullet}(\bullet, \mathrm{w} 3)=3 \leq d_{\bullet}(\bullet, \mathrm{w} 6)$; Lemma 13 showed $\mathrm{O}$ could never win neither T2, T3 nor $\mathrm{T} 4$ during $\bullet \in \ell(\mathrm{B}, \mathrm{P})$ by $d_{\bullet}(\bullet, \mathrm{V}) \leq 2=d_{\circ}(\mathrm{L}, \mathrm{T} 3), d_{\bullet}(\bullet, \mathrm{W}) \leq 3=d_{\circ}(\mathrm{L}, \mathrm{T} 2)$, and $d_{\bullet}(\bullet, \mathrm{P})=1<2=d_{\circ}(\mathrm{L}, \mathrm{T} 4)$. After that, $\mathrm{O}$ must take $(\mathrm{L}, \mathrm{G}) \rightarrow(\mathrm{K}, \mathrm{G})$ for blocking $\mathrm{w} 3$, or $(\mathrm{L}, \mathrm{G}) \rightarrow(\mathrm{J}, \mathrm{G})$ to surpass w3 by $d_{\circ}(\mathrm{J}, \mathrm{T} 4)=1<2=d_{\bullet}(\mathrm{G}, \mathrm{w} 3)$. However, then $\bullet$ could $\operatorname{march}(\{\mathrm{K}, \mathrm{J}\}, \mathrm{G}) \rightarrow(\{\mathrm{K}, \mathrm{J}\}, \mathrm{S})$, protect $\mathrm{T} 4$ by $d_{0}(\mathrm{~S}, \mathrm{R})=d_{0}(\{\mathrm{~K}, \mathrm{~J}\}, \mathrm{T} 4)=1$, and win either $\mathrm{w} 3$ or $\mathrm{w} 4$ by $d_{\bullet}(\mathrm{S}, \mathrm{w} 3)=d_{\bullet}(\mathrm{S}, \mathrm{w} 4)=2<d_{\circ}(\{\mathrm{K}, \mathrm{J}\}, \mathrm{T} 2)=d_{\circ}(\{\mathrm{K}, \mathrm{J}\}, \mathrm{T} 5)=3$; Lemma 13 showed $O$ could never win either T3 or T4.

If $\mathrm{O}$ at $\mathrm{D}$ went up $(\mathrm{D}, \mathrm{B}) \rightarrow(\mathrm{U}, \mathrm{B})$, $\bullet$ could march $(\mathrm{U}, \mathrm{B}) \rightarrow(\mathrm{U}, \mathrm{G})$, protect $\mathrm{T} 3$, and win w3 by Lemma 13 . Hence, $\mathrm{O}$ must proceed $(\mathrm{D}, \mathrm{B}) \rightarrow(\mathrm{F}, \mathrm{B})$, and Lemma 13 forces - $:(\mathrm{F}, \mathrm{B}) \rightarrow(\mathrm{F}, \mathrm{D})$, the claimed moves from the left.

When they come from the right $(\mathrm{I}, \mathrm{H})$, Lemma 13 forces $(\mathrm{I}, \mathrm{H}) \rightarrow(\mathrm{L}, \mathrm{I})$. After that, if $\mathrm{O}$ took $(\mathrm{L}, \mathrm{I}) \rightarrow(\mathrm{FL}-\{\mathrm{D}\}, \mathrm{I})$, he would lose to $\bullet^{\prime} \mathrm{s}(\overline{\mathrm{FL}}-\{\mathrm{D}\}, \mathrm{I}) \rightarrow(\overline{\mathrm{FL}}-\{\mathrm{D}\}, \mathrm{K})$ since $\mathrm{O} \in \overline{\mathrm{FL}}-\{\mathrm{D}\}$ could never win T3 by $d_{\bullet}(\mathrm{K}, \mathrm{V})=1 \leq d_{\circ}(\mathrm{O}, \mathrm{T} 3)$ and lose w3 by $d_{\bullet}(\mathrm{K}, \mathrm{w} 3)=2<d_{\circ}(\mathrm{O}, \mathrm{T} 2)=d_{\circ}(\mathrm{O}, \mathrm{T} 4)=d_{\circ}(\mathrm{O}, \mathrm{T} 6)=3$. If $\mathrm{O}$ took $(\mathrm{L}, \mathrm{I}) \rightarrow(\mathrm{D}, \mathrm{I})$ and got $d_{\mathrm{o}}(\mathrm{D}, \mathrm{T} 2)=d_{\mathrm{o}}(\mathrm{D}, \mathrm{T} 3)=2$, he would lose as follows. The responds $(\mathrm{D}, \mathrm{I}) \rightarrow(\mathrm{D}, \mathrm{K})$ to protect both $\mathrm{T} 2$ and $\mathrm{T} 3, \mathrm{O}:(\mathrm{D}, \mathrm{K}) \rightarrow(\mathrm{C}, \mathrm{K})$ to survive $\mathrm{w} 3$ by $\mathrm{O} \notin \ell(\mathrm{T} 2, \mathrm{C}) \Rightarrow d_{\bullet}(\mathrm{K}, \mathrm{w} 3)=$ $d_{\circ}(\mathrm{O}, \mathrm{T} 2)=2, \bullet:(\mathrm{C}, \mathrm{K}) \rightarrow(\mathrm{C}, \mathrm{N})$ for protecting $\mathrm{T} 2$ and $\mathrm{O}:(\mathrm{C}, \mathrm{N}) \rightarrow(\mathrm{G}, \mathrm{N})$ to block $\bullet$ 's access to w3; if $\mathrm{O}$ did not, $\mathrm{O} \in \mathrm{BP}-\{\mathrm{C}, \mathrm{G}\}$ would lose w3 by $d_{\bullet}(\mathrm{N}, \mathrm{w} 3)=$ $d_{\circ}(\mathrm{O}, \mathrm{T} 2)=2 \leq d_{\circ}(\mathrm{O}, \mathrm{T} 1)=d_{\circ}(\mathrm{O}, \mathrm{T} 3)$. After that, $\bullet$ proceeds $(\mathrm{G}, \mathrm{N}) \rightarrow(\mathrm{G}, \mathrm{N} 1)$, to the stop N1 $\in$ NG nearest to $G$ on the assumption $|N G| \geq 1$, then $(G, N 1) \rightarrow((S, G) \rightarrow)(K, S)$ for $\bigcirc$ to keep blocking w3. Finally, wins either w3 or w4, as argued in the second turn of the from-the-left case. Thus, $\mathrm{O}$ must go (L,I) $\rightarrow(\mathrm{F}, \mathrm{I})$ and Lemma 13 forces - $:(\mathrm{L}, \mathrm{I}) \rightarrow(\mathrm{F}, \mathrm{L})$, the claimed moves from-the-right. 


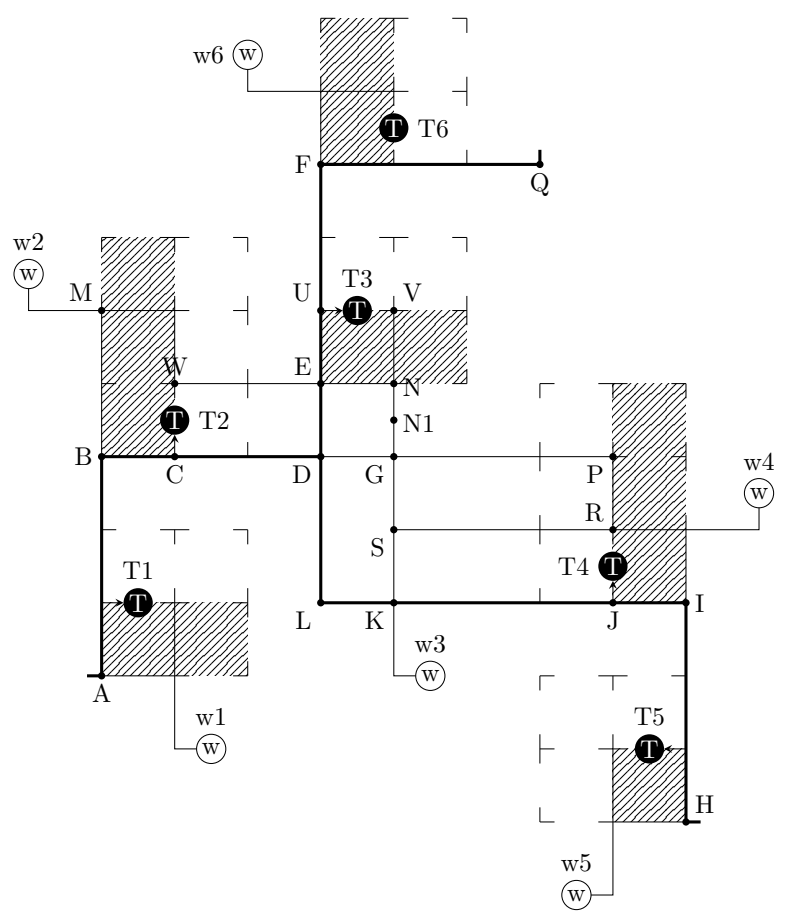

Figure 103. Junction.

\subsection{Starts}

Starts are the gates where the free men alternate their roles in the escape-and-chase game. Figure 104 is a B-start gate where the free $\bigcirc$ turns from escaper to chaser and the from chaser to escaper.

Lemma 17. Suppose $|O I|=0$ and $|L O| \leq|O|$. Figure 104 forces $(O, \bullet)=(B, A) \rightarrow(D, B) \rightarrow$ $(F, C) \rightarrow(H, K) \rightarrow \cdots \rightarrow(\bullet, O)=(P, L) \rightarrow \cdots$.

Proof. Lemma 13 forces $(B, A) \rightarrow(D, B)$, where $A B$ has the gadget congruent with the left's one on BC. In the second turn, $-\mathrm{B}$ can protect both T2 and T3 by $d_{\bullet}(\mathrm{B}, \mathrm{M})=2$ and $d_{\bullet}(\mathrm{B}, \mathrm{J})=3$ against $d_{\circ}(\mathrm{D}, \mathrm{T} 2)=2$ and $d_{\circ}(\mathrm{D}, \mathrm{T} 3)=3$, so $\mathrm{O}:(\mathrm{D}, \mathrm{B}) \rightarrow(\mathrm{F}, \mathrm{B})$ blocks -'s access to $\mathrm{w} 2$ at $\mathrm{I}$ and survives by $\mathrm{O} \notin \ell(\mathrm{F}, \mathrm{H}) \Rightarrow d_{\bullet}(\mathrm{B}, \mathrm{I})=d_{\circ}(\mathrm{O}, \mathrm{I})=3$, then - $:(\mathrm{F}, \mathrm{B}) \rightarrow(\mathrm{F}, \mathrm{C})$ to keep protecting T3. Similarly, $(\mathrm{F}, \mathrm{C}) \rightarrow(\mathrm{H}, \overline{\mathrm{KC}}-\{\mathrm{C}\})$ in the third turn.

After that, the men may stick to $\bullet \in \mathrm{KC}$ and $\mathrm{O} \in \mathrm{IH}$. If one man reaches $\{\mathrm{K}, \mathrm{I}\}$, the other must do and make a position $(\bullet, \mathrm{O})=(\mathrm{K}, \mathrm{I})$ in the next turn for $\mathrm{O}$ (resp. $\bullet$ ) to block -'s (resp. O's) access to w2 (resp. w3).

After that, to not delay the game, - must go immediately to $\mathrm{L}$ and beyond by $\widetilde{\mathrm{R} .4}$ since $O$ can wait in $\mathrm{O}$ longer than $\bullet$ in $\mathrm{LO}$ on the assumption $|\mathrm{OI}|=0$ and $|\mathrm{LO}| \leq|\mathrm{O}|$.

Consequently, Lemma 13's dual forces $(\bullet, \mathrm{O})=(\mathrm{K}, \mathrm{I}) \rightarrow(\mathrm{L}, \mathrm{LI}) \rightarrow(\mathrm{P}, \mathrm{L})$. 


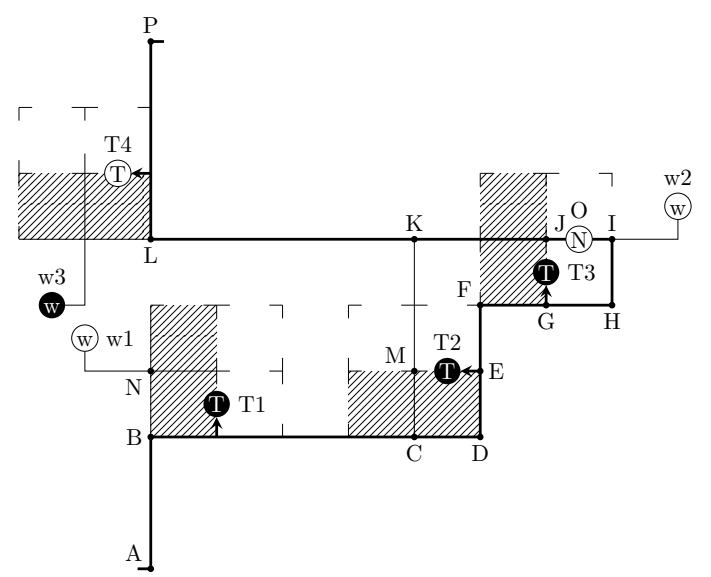

Figure 104. B-start.

\subsection{Switches}

Figure 105 places men (belonging to no gadget) at stops $\mathrm{P}, \mathrm{M}$ (as well as $\mathrm{R}, \mathrm{U}, \mathrm{P}^{\prime}, \mathrm{M}^{\prime}$, $\mathrm{R}^{\prime}, \mathrm{U}^{\prime}$ ) such that a man at $\mathrm{P}$ cannot move to any of the left, right, or down directions due to obstacles, and a man at M cannot go to the left, up, or down; M's invasion to w2 forces his defeat as shown in Figures 77-80.

Lemma 18. The men in Figure 105 are dead-locked except the bounded men on $S 1 M^{\prime}$ and $S 2 U^{\prime}$, who can move only horizontally.

Proof. We have already shown all gadgets inside Figure 105 dead-locked. If M's $\bigcirc$ moved horizontally, $\mathrm{P}^{\prime} \mathrm{s}$ would march to w2 and win, so the men standing on $\mathrm{M}, \mathrm{U}^{\prime}, \mathrm{M}^{\prime}, \mathrm{U}^{\prime}$ are unmovable. Thus, the men at $\mathrm{P}, \mathrm{R}, \mathrm{P}^{\prime}, \mathrm{R}^{\prime}$ are by construction. If the bounded $\mathrm{O}$ on $\mathrm{S} 1 \mathrm{M}^{\prime}$ moved vertically, Lemma 11 would force BLACK's win by first moving $\mathrm{M}^{\prime \prime}$ s to the S1's right side checkmate, and secondly M's to the other checkmate.

The at $Z^{\prime}$ moves horizontally to BLOCK the free $O^{\prime}$ s passing through a $W$-winning lane crossing at $Z^{\prime}$. Concretely speaking, $Z^{\prime}$ is one of the stops $Z_{i, s w}^{\prime}$ in Figure 106 (placed at the end of this section). Bounded- standing on $Z^{\prime}$ take five moves to reach the nearest $W$-weak point $w\left(Z^{\prime}\right)$ in the $W$-win lane; we write $d_{\circ}\left(Z^{\prime}, w\left(Z^{\prime}\right)\right)=5$. All of these $G, G^{\prime}, Z$, and $Z^{\prime}$ should take a long distance away from the other switch parts.

The left-hand side of Figure 105 configures $|\mathrm{S} 1 \mathrm{M}|=|\mathrm{S} 2 \mathrm{U}|,|\mathrm{N} 1 \mathrm{~L}|=0,|\mathrm{FN} 1| \leq|\mathrm{N} 1|$, $|\mathrm{BT} 1| \leq|\mathrm{CD}|=|\mathrm{IK}|$ (by placing a W-parking on CD), and $|\mathrm{CD}|+|\mathrm{EN} 1| \leq|\mathrm{N} 1|$; the right-hand side does the same. We make a one-to-one correspondence between S1M and S2U along with $\mathrm{E} \leftrightarrow \mathrm{L}$ and write $\mathrm{O} \equiv \boldsymbol{\text { when }} \mathrm{O} \in \mathrm{S} 1 \mathrm{M}$ and $\bullet \in \mathrm{S} 2 \mathrm{U}$ occupy the corresponding places.

We call Figure 105 a $W$-switch since it takes either the ON or OFF state to check the winning conditions. When WHITE comes there to change between ON and OFF, he swaps the free men with the bounded men. When the free men reach there, we denote them as $\left\{\bigcirc_{f}, \bigcirc_{f}\right\}$ to distinguish from the bounded men $\left\{\mathrm{O}_{b}, \boldsymbol{\bigcirc}_{b}\right\}$ in the right-hand side of Figure 105. WHITE can choose which men's sides become the next free men (the remainders are the bounded men). Figure 105 shows an OFF state having $\left(\mathrm{O}_{b}, \mathbf{O}_{b}\right) \in\left(\mathrm{S}_{1} \mathrm{M}^{\prime}, \mathrm{S}^{\prime} \mathrm{U}^{\prime}\right)$.

Lemma 19. Suppose WHITE's move incurs $\bigcirc_{f} \notin S 1 M$ and $O_{b} \notin S 1 M^{\prime}, B L A C K$ can win by two movements.

Proof. Similar to Lemma 18's proof. If $\mathrm{O}_{b}: \mathrm{E}^{\prime} \rightarrow \ell\left(\mathrm{F}^{\prime}, \mathrm{L}^{\prime}\right)-\left\{\mathrm{E}^{\prime}\right\}$ incurs it, BLACK's first move is at $\mathrm{M}$ to the left checkmate of S1. Lemma 11 forces $O_{b}$ to come back $\ell\left(\mathrm{F}^{\prime}, \mathrm{L}^{\prime}\right)-\left\{\mathrm{E}^{\prime}\right\} \rightarrow \mathrm{E}^{\prime}$, presenting BLACK a winning repetition $\left(\mathrm{E}^{\prime}, \mathrm{M}\right) \rightarrow\left(\ell\left(\mathrm{F}^{\prime}, \mathrm{L}^{\prime}\right)-\right.$ $\left.\left\{\mathrm{E}^{\prime}\right\}, \mathrm{S} 1\right) \rightarrow\left(\mathrm{E}^{\prime}, \mathrm{M}\right)$. 


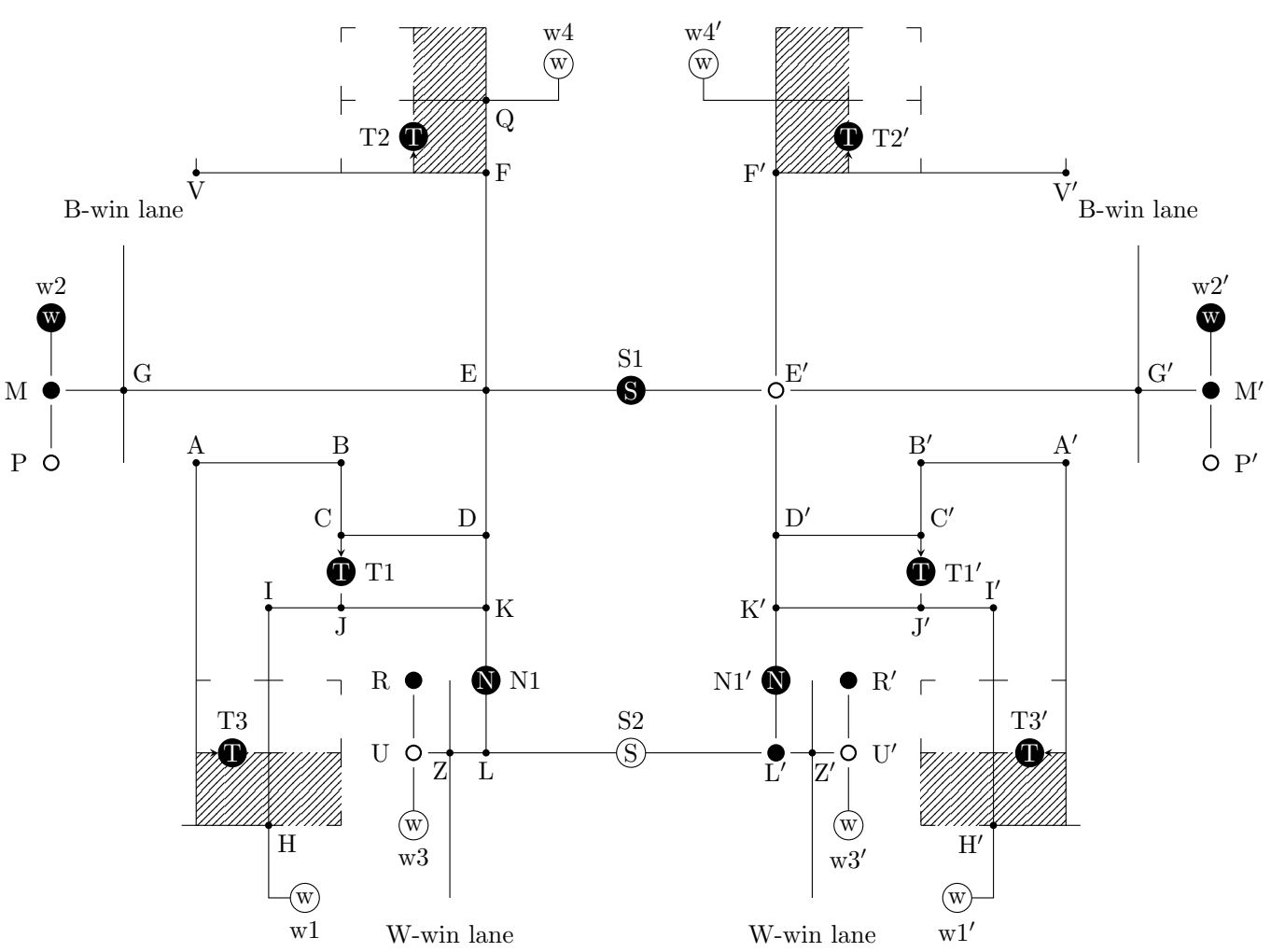

Figure 105. W-switch OFF.

Lemma 20. Figure 105 for WHITE to move forces either $\left(\mathrm{O}_{f}, \boldsymbol{\bullet}_{f}, \mathrm{O}_{b}, \boldsymbol{\bullet}_{b}\right)=\left(E, S 2 U, E^{\prime}, S 2 U^{\prime}\right)$ $\stackrel{*}{\rightarrow}\left(S 1 M, S 2 U, V^{\prime}, F^{\prime}\right)$ or $\left(V, F, S 1 M^{\prime}, S 2 U^{\prime}\right)$, i.e., the switch $O N$ or $O F F$.

Proof. If WHITE will switch ON, he must move $\left(\mathrm{O}_{b}, \mathbf{\bullet}_{b}\right)=\left(\mathrm{E}^{\prime}, \mathrm{Y}^{\prime}\right) \rightarrow\left(\mathrm{F}^{\prime}, \mathrm{Y}^{\prime}\right)$ for the following reason in any case of $\mathrm{Y}^{\prime}=\mathrm{L}^{\prime}$ or $\mathrm{Y}^{\prime} \neq \mathrm{L}^{\prime}$ (i.e., $\mathrm{Y}^{\prime} \in \mathrm{S} 2 \mathrm{U}^{\prime}-\mathrm{L}^{\prime}$ ). Any horizontal move $\mathrm{O}_{b}:\left(\mathrm{E}^{\prime}, \mathrm{Y}^{\prime}\right) \rightarrow\left(\mathrm{X}^{\prime}, \mathrm{Y}^{\prime}\right), \mathrm{X1}^{\prime} \in \mathrm{S}^{\prime} \mathrm{M}^{\prime}-\left\{\mathrm{L}^{\prime}\right\}$ forces WHITE to lose $\mathrm{w} 4^{\prime}$ by $\mathrm{Y}^{\prime}=$ $\mathrm{L}^{\prime} \Rightarrow d_{\bullet}\left(\mathrm{L}^{\prime}, \mathrm{w} 4^{\prime}\right)=3 \leq 4=d_{\circ}\left(\mathrm{X}^{\prime}, \mathrm{w} 4^{\prime}\right)$, or incurring BLACK's winning repetition by $\mathrm{Y}^{\prime} \neq \mathrm{L}^{\prime} \Rightarrow\left(\mathrm{O}_{b}, \boldsymbol{\bullet}_{b}\right)=\left(\mathrm{E}^{\prime}, \mathrm{Y}^{\prime}\right) \rightarrow\left(\mathrm{X}^{\prime}, \mathrm{Y}^{\prime}\right) \rightarrow\left(\mathrm{X}^{\prime}, \mathrm{L}^{\prime}\right) \rightarrow\left(\mathrm{E}^{\prime}, \mathrm{L}^{\prime}\right) \rightarrow\left(\mathrm{E}^{\prime}, \mathrm{Y}^{\prime}\right)$ where the same analysis forces WHITE's comeback $\left(\mathrm{X}^{\prime}, \mathrm{L}^{\prime}\right) \rightarrow\left(\mathrm{E}^{\prime}, \mathrm{L}^{\prime}\right)$. The $\mathrm{O}_{b}$ could never win $\mathrm{T}^{\prime}$ against ${ }_{b}$ 's protection by $d_{\bullet}\left(\mathrm{Y}^{\prime}, \mathrm{J}^{\prime}\right) \leq 3=d_{\circ}\left(\mathrm{E}^{\prime}, \mathrm{T}^{\prime}\right)$. R.4 forbids $\mathrm{O}_{b}$ to stay in $\mathrm{F}^{\prime} \mathrm{N} 1^{\prime}$ since $\boldsymbol{\theta}_{b}$ can wait for it in $\mathrm{N}^{\prime}$ on the assumption $\left|\mathrm{N} 1^{\prime} \mathrm{L}^{\prime}\right|=0$ and $\left|\mathrm{F}^{\prime} \mathrm{N} 1^{\prime}\right| \leq\left|\mathrm{N} 1^{\prime}\right|$. Eventually, $\mathrm{O}_{b}$ must go to $\mathrm{F}^{\prime}$ immediately to not delay the game.

Similarly, BLACK must respond as follows: $\mathrm{Y}^{\prime} \neq \mathrm{L}^{\prime} \Rightarrow\left(\mathrm{O}_{b}, \boldsymbol{\bullet}_{b}\right)=\left(\mathrm{F}^{\prime}, \mathrm{Y}^{\prime}\right) \rightarrow\left(\mathrm{F}^{\prime}, \mathrm{L}^{\prime}\right)$ for surviving $\mathrm{T} 2^{\prime}$ by $d_{\circ}\left(\mathrm{F}^{\prime}, \mathrm{T}^{\prime}\right)=2<3=d_{\circ}\left(\mathrm{Y}^{\prime}, \mathrm{T} 2^{\prime \prime}\right.$ s protector $)<4=d_{\circ}\left(\mathrm{Y}^{\prime}, \mathrm{w} 4^{\prime}\right)$. The $\mathrm{Y}^{\prime}=\mathrm{L}^{\prime}$ case forces either $\bullet_{b}$ 's vertical move (by the same analysis) or $\boldsymbol{\bullet}_{f}$ 's horizontal one since $\bullet_{f} \notin \ell(\mathrm{S} 2, \mathrm{U}) \Rightarrow d_{\circ}\left(\mathrm{F}^{\prime}, \mathrm{T}^{\prime}\right)=2<1+2=d_{\circ}\left(\bullet_{f}, \ell(\mathrm{S} 2, \mathrm{U})\right)+$ $d_{0}\left(\mathrm{~L}^{\prime}, \mathrm{T} 2^{\prime \prime}\right.$ s protector $)$.

Lemma 13 makes $\left(\mathrm{O}_{b}, \mathbf{\bullet}_{b}\right)=\left(\mathrm{F}^{\prime}, \mathrm{Y}^{\prime}\right) \rightarrow\left(\mathrm{V}^{\prime}, \mathrm{F}^{\prime}\right)$ happening in the second turn. The same argument induces $\left(\mathrm{O}_{f}, \boldsymbol{\bullet}_{f}\right)=(\mathrm{E}, \mathrm{L}) \stackrel{*}{\rightarrow}(\mathrm{V}, \mathrm{F})$ if WHITE will switch OFF.

The free men may get into Figure 105 from the left and reach to $\left(\mathrm{O}_{f}, \boldsymbol{\bullet}_{f}\right)=(\mathrm{A}, \mathrm{H})$ for changing its state. Notice that the left side of Figure 105 connects to the outside area via Figure 101's right side structure as $(\mathrm{A}, \mathrm{H})=(\mathrm{C}, \mathrm{K})$.

Lemma 21. Figure 105 forces $\left(\mathrm{O}_{f}, \boldsymbol{\bullet}_{f}\right)=(A, H) \rightarrow(B, I) \rightarrow(C, I K-\{I\})$ or $(A, H) \rightarrow$ $(B, I) \rightarrow(T 1, J) \rightarrow(C, I K-\{I\})$.

Proof. Similar to Lemma 14's proof. In the first turn, $\mathrm{O}_{f}$ must proceed $(\mathrm{A}, \mathrm{H}) \rightarrow(\mathrm{B}, \mathrm{H})$ to survive $\mathrm{w} 1$ by $\mathrm{O}_{f} \notin \ell(\mathrm{B}, \mathrm{C}) \Rightarrow d_{\bullet}(\mathrm{H}, \mathrm{w} 1)=2 \leq d_{\circ}(\mathrm{O}, \mathrm{T} 1)$, then $\bullet_{f}:(\mathrm{B}, \mathrm{H}) \rightarrow(\mathrm{B}, \mathrm{I})$ to survive T1 by $\bullet_{f} \in \ell(\mathrm{I}, \mathrm{H})-\{\mathrm{I}\} \Rightarrow d_{\circ}(\mathrm{B}, \mathrm{T} 1)=1 \leq d_{\bullet}\left(\bullet_{f}, \mathrm{w} 1\right) \leq 2=d_{\bullet}\left(\bullet_{f}, \mathrm{~J}\right)$. In the 
second turn, WHITE can choose either $(\mathrm{B}, \mathrm{I}) \rightarrow(\mathrm{T} 1, \mathrm{I}) \rightarrow(\mathrm{T} 1, \mathrm{~J}) \rightarrow(\mathrm{C}, \mathrm{J}) \rightarrow(\mathrm{C}, \mathrm{IK}-\{\mathrm{I}\})$ or $(\mathrm{B}, \mathrm{I}) \rightarrow(\mathrm{C}, \mathrm{I}) \rightarrow(\mathrm{C}, \mathrm{IK}-\{\mathrm{I}\}) ; \widetilde{\mathrm{R} .4}$ forbids $\mathrm{O}_{f}$ to stay in BT1 since $\bullet_{f}$ can wait for it in IK on the assumption $|\mathrm{BT} 1| \leq|\mathrm{IK}|$.

Lemma 22. If WHITE starts Figure 105 from $\left(\mathrm{O}_{f}, \boldsymbol{\bullet}_{f}\right)=(A, H)$, BLACK can survive.

Proof. Suppose WHITE would never choose to move $O_{f}$ to $\overline{E F}-\{E\}$ or $O_{b}$ to $\overline{E^{\prime} F^{\prime}}-\left\{E^{\prime}\right\}$; if WHITE moved $O_{f}$ to $\overline{\mathrm{EF}}-\{\mathrm{E}\}, \bullet_{f}$ could survive by chasing $\mathrm{O}_{f}$ aggressively (to the nearest stop of $O_{f}$ ) and getting $O_{f}$ out of the switch. Then, BLACK wins by making an $\widetilde{\mathbf{R}_{\text {.4}}}$ 's winning repetition as follows. The assumption $|\mathrm{CD}|+|\mathrm{EN} 1| \leq|\mathrm{N} 1|$ allows the following one-to-one correspondence $\phi$ between the free men's positions $\mathrm{O}_{f} \leftrightarrow \bullet_{f}$ : Let N1 contain the disjoint union of $\mathrm{N}_{c d}$ and $\mathrm{N} 1_{e n}$ of cardinalities $|\mathrm{CD}|$ and $|\mathrm{EN} 1| . \mathrm{T} 1 \leftrightarrow \mathrm{J}, \mathrm{C} \leftrightarrow \mathrm{K}$, $\mathrm{CD} \leftrightarrow \mathrm{N} 1_{c d}, \mathrm{EN} 1 \leftrightarrow \mathrm{N} 1_{e n}$, and $\mathrm{E} \leftrightarrow \mathrm{L}$. Lemma 21 guides $\left(\mathrm{O}_{f}, \bullet_{f}\right)=(\mathrm{A}, \mathrm{H}) \stackrel{*}{\rightarrow}(\mathrm{C}, \mathrm{K})$. After that, $\bullet_{f}$ mimics $O_{f}$ 's move along with $\phi$ to preserve $\bullet_{f}=\phi\left(O_{f}\right)$ at the beginning of every WHITE's turn. Similarly, $\bullet_{b}$ mimics $\mathrm{O}_{b}$ 's one to keep $\bullet_{b} \equiv \mathrm{O}_{b}$ (except when BLACK can win immediately due to $\mathrm{O}_{b}$ 's wrong move, e.g., if $\left(\boldsymbol{\bullet}_{f}, \boldsymbol{\bullet}_{b}\right) \in \mathrm{S} 2 \mathrm{U} \times\left\{\mathrm{L}^{\prime}\right\}$ and $\mathrm{O}_{b}: \mathrm{E}^{\prime} \rightarrow \mathrm{G}^{\prime}$ then $\boldsymbol{\bullet}_{b}$ can win $\mathrm{w}^{\prime}$ as shown in Lemma 20).

In the repetition, WHITE could never hope to win $\mathrm{T} 1, \mathrm{~T} 2, \mathrm{~T}^{\prime}, \mathrm{T} 2^{\prime}$, or $\mathrm{w}(\mathrm{G})$ as shown in Lemma 20; $\mathrm{O}_{f} \in \mathrm{S} 1 \mathrm{M}-\{\mathrm{E}\}$ forces WHITE to lose w4. He could never win $\mathrm{w}\left(\mathrm{G}^{\prime}\right)$ since $d_{\bullet}\left(\bullet_{f}, \mathrm{~L}\right) \leq d_{\circ}\left(\mathrm{O}_{f}, \mathrm{E}\right)$ at the beggining of every WHITE's turn and $d_{\bullet}\left(\bullet_{b}, \mathrm{w}^{\prime}\right) \leq 4<$ $5 \leq d\left(\mathrm{O}_{b}, \mathrm{w}\left(\mathrm{G}^{\prime}\right)\right)$ by Figure 106's construction. Eventually, $\widetilde{\mathrm{R} .4}$ makes $\left(\mathrm{O}_{f}, \mathrm{O}_{b}, \boldsymbol{\bullet}_{f}, \boldsymbol{\bullet}_{b}\right)=$ $\left(\mathrm{E}, \mathrm{E}^{\prime}, \mathrm{L}, \mathrm{L}^{\prime}\right)$ happen at the beginning of WHITE's turn since $\bullet_{f}$ can wait for it on $\mathrm{N} 1_{s w}$, yielding WHITE's defeat.

Lemma 23. If WHITE starts Figure 105 from $\left(\mathrm{O}_{f}, \boldsymbol{\bullet}_{f}\right)=(A, H)$, WHITE can switch ON or OFF as he likes.

Proof. Similar to Lemma 22's demonstration. Lemma 16 guides $(\mathrm{A}, \mathrm{H}) \stackrel{*}{\rightarrow}(\mathrm{C}, \mathrm{J}) \rightarrow$ $(\mathrm{C}, \mathrm{K}) \rightarrow(\mathrm{D}, \mathrm{K}) \rightarrow(\mathrm{D}, \mathrm{Y})$ with $\mathrm{Y} \in \mathrm{DL} \cup\{\mathrm{L}\}-\{\mathrm{K}\}$, where $\bullet_{f}$ must go $(\mathrm{C}, \mathrm{J}) \rightarrow(\mathrm{C}, \mathrm{K})$; $\widetilde{\mathrm{R} .4}$ forbids ${ }_{f}$ 's stay in IK since $\mathrm{O}_{f}$ can wait it in $\mathrm{CD}$ on the assumption $|\mathrm{CD}|=|\mathrm{IK}|$.

WHITE's next move depends on either $\mathrm{O}_{b}=\mathrm{E}^{\prime}$ or $\mathrm{O}_{b} \neq \mathrm{E}^{\prime}$ (i.e., $\mathrm{O}_{b} \in \mathrm{S} \mathrm{M}^{\prime}-\left\{\mathrm{E}^{\prime}\right\}$ ). In the former case, WHITE can move to realize $\left(\mathrm{O}_{f}, \boldsymbol{\bullet}_{f}, \mathrm{O}_{b}, \boldsymbol{\bullet}_{b}\right)=\left(\mathrm{D}, \mathrm{Y}, \mathrm{E}^{\prime}, \mathrm{Y}^{\prime}\right) \rightarrow$ $\left(\mathrm{E}, \mathrm{Y}, \mathrm{E}^{\prime}, \mathrm{Y}^{\prime}\right) \rightarrow\left(\mathrm{E}, \mathrm{Y} 1, \mathrm{E}^{\prime}, \mathrm{Y}^{\prime}\right)$ or $\left(\mathrm{E}, \mathrm{Y}, \mathrm{E}^{\prime}, \mathrm{Y}^{\prime}\right) \stackrel{*}{\rightarrow}\left(\mathrm{S} 1 \mathrm{M}, \mathrm{S} 2 \mathrm{U}, \mathrm{V}^{\prime}, \mathrm{F}^{\prime}\right)$ or $\left(\mathrm{V}, \mathrm{F}, \mathrm{S}^{\prime} \mathrm{M}^{\prime}, \mathrm{S}^{2} \mathrm{U}^{\prime}\right)$ as shown in Lemma 20, where $\mathrm{Y}^{\prime} \in \mathrm{S} 2 \mathrm{U}^{\prime}$ and $\left(\mathrm{Y} 1, \mathrm{Y}^{\prime}\right) \in(\mathrm{S} 2 \mathrm{U} \cup \mathrm{EL}) \times\left(\mathrm{S} 2 \mathrm{U}^{\prime} \cup \mathrm{E}^{\prime} \mathrm{L}^{\prime}\right)-\mathrm{EL} \times$ $\mathrm{E}^{\prime} \mathrm{L}^{\prime}$. The latter case is the same by $\left(\mathrm{O}_{f}, \bullet_{f}, \mathrm{O}_{b}, \mathbf{\bullet}_{b}\right)=\left(\mathrm{D}, \mathrm{Y}, \mathrm{X}^{\prime}, \mathrm{Y}^{\prime}\right) \rightarrow\left(\mathrm{D}, \mathrm{Y}, \mathrm{E}^{\prime}, \mathrm{Y}^{\prime}\right) \rightarrow$ $\left(\mathrm{D}, \mathrm{Y} 1, \mathrm{E}^{\prime}, \mathrm{Y}^{\prime}\right) \rightarrow\left(\mathrm{E}, \mathrm{Y} 1, \mathrm{E}^{\prime}, \mathrm{Y}^{\prime}\right) \rightarrow\left(\mathrm{E}, \mathrm{Y} 1, \mathrm{E}^{\prime}, \mathrm{Y}^{\prime}\right) \stackrel{*}{\rightarrow}\left(\mathrm{S} 1 \mathrm{M}, \mathrm{S} 2 \mathrm{U}, \mathrm{V}^{\prime}, \mathrm{F}^{\prime}\right)$ or $\left(\mathrm{V}, \mathrm{F}, \mathrm{S}^{\prime} \mathrm{M}^{\prime}, \mathrm{S}^{\prime} \mathrm{U}^{\prime}\right)$. BLACK may move $\mathrm{O}_{f}$ twice or $\mathrm{O}_{b}$ twice to reach $\left(\mathrm{O}_{f}, \boldsymbol{\bullet}_{f}, \mathrm{O}_{b}, \mathbf{\bullet}_{b}\right)=\left(\mathrm{D}, \mathrm{Y}, \mathrm{X}^{\prime}, \mathrm{Y}^{\prime}\right) \rightarrow$ $\left(\mathrm{D}, \mathrm{Y}, \mathrm{E}^{\prime}, \mathrm{Y}^{\prime}\right) \rightarrow\left(\mathrm{D}, \mathrm{Y} 1, \mathrm{E}^{\prime}, \mathrm{Y}^{\prime}\right) \rightarrow\left(\mathrm{E}, \mathrm{Y} 1, \mathrm{E}^{\prime}, \mathrm{Y}^{\prime}\right) \rightarrow\left(\mathrm{E}, \mathrm{Y} 2, \mathrm{E}^{\prime}, \mathrm{Y}^{\prime}\right)$ or $\left(\mathrm{O}_{f}, \bullet_{f}, \mathrm{O}_{b}, \mathbf{\bullet}_{b}\right)=$ $\left(\mathrm{D}, \mathrm{Y}, \mathrm{X}^{\prime}, \mathrm{Y}^{\prime}\right) \stackrel{*}{\rightarrow}\left(\mathrm{E}, \mathrm{Y}, \mathrm{E}^{\prime}, \mathrm{Y} 2^{\prime}\right)$, where $\left(\{\mathrm{Y} 1, \mathrm{Y} 2\},\left\{\mathrm{Y}^{\prime}, \mathrm{Y} 2^{\prime}\right\}\right) \subset(\mathrm{S} 2 \mathrm{U} \cup \mathrm{EL}) \times\left(\mathrm{S} \mathrm{U}^{\prime} \cup \mathrm{E}^{\prime} \mathrm{L}^{\prime}\right)-$ $\mathrm{EL} \times \mathrm{E}^{\prime} \mathrm{L}^{\prime}$. In any case, Lemma 20 allowed WHITE to switch ON or OFF.

As shown in Lemma 22, BLACK can never hope to win $\mathrm{w}(Z)$ nor $\mathrm{w}\left(\mathrm{Z}^{\prime}\right)$ in these moves since $\left(\mathrm{O}_{f}, \mathrm{O}_{b}, \bullet_{f}\right) \in\{\mathrm{E}\} \times \mathrm{F}^{\prime} \mathrm{L}^{\prime} \times \mathrm{S} 2 \mathrm{U} \Rightarrow d_{\circ}\left(\mathrm{O}_{b}, \mathrm{E}^{\prime}\right)+d_{\circ}(\mathrm{E}, \mathrm{T} 2)=1+3<5=$

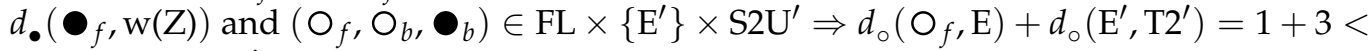
$5=d_{\bullet}\left(\bullet_{b}, \mathrm{w}\left(Z^{\prime}\right)\right)$ by Figure 106's construction.

WHITE may choose to enter from the wrong-side entrance of Figure 105, where the right men have already resided, but he cannot defeat BLACK nor change the switch's state.

Lemma 24. If Figure 105 starts from $\left(\mathrm{O}_{f}, \boldsymbol{\bullet}_{f}, \mathrm{O}_{b}, \boldsymbol{\bullet}_{b}\right) \in(A, H, S 1 M, S 2 U)$ in WHITE's turn, $B L A C K$ can survive.

Proof. Similar to Lemma 22's proof. Suppose WHITE would never move $O_{f}$ to $\overline{E F}-\{E\}$ and prove WHITE to lose. Lemma 21 guides $\left(\mathrm{O}_{f}, \bullet_{f}\right)=(\mathrm{A}, \mathrm{H}) \stackrel{*}{\rightarrow}(\mathrm{C}, \mathrm{K}) \rightarrow(\mathrm{CD}-$ $\{\mathrm{C}\}, \mathrm{N} 1)$. The assumption $|\mathrm{CD}|+|\mathrm{EN} 1| \leq|\mathrm{N} 1|$ allows $\bullet_{f}$ to wait in N1 until $\widetilde{\mathrm{R} .4}$ ( and Lemma 19) force $\left\{\mathrm{O}_{f}, \mathrm{O}_{b}\right\} \cap \ell(\mathrm{F}, \mathrm{L})=\varnothing$ or $\left(\mathrm{O}_{f}, \mathrm{O}_{b}\right) \in \mathrm{S} 1 \mathrm{M} \times(\mathrm{B}$-win-lane $-\{\mathrm{G}\})$. 
The former case forces BLACK to win w4 as shown in Lemma 20, and the latter one does it at $\mathrm{w} 1$ by $d_{\circ}\left(\mathrm{O}_{b}, \ell(\mathrm{S} 1, \mathrm{M})\right)=1 \Rightarrow d_{\bullet}(\mathrm{N} 1, \mathrm{w} 1)=d_{\circ}\left(\mathrm{O}_{b}, \mathrm{w}(\mathrm{G})\right)=4=1+3 \leq$ $d_{\circ}\left(\mathrm{O}_{b}, \ell(\mathrm{S} 1, \mathrm{M})\right)+d_{\circ}\left(\mathrm{O}_{f}, \mathrm{~T} 1\right)$ since $d_{\circ}(\mathrm{G}, \mathrm{w}(\mathrm{G}))=5$ by Figure 106 's construction. The same analysis prohibits WHITE to win $w(G)$, so WHITE must lose by $\widetilde{R .4}$.

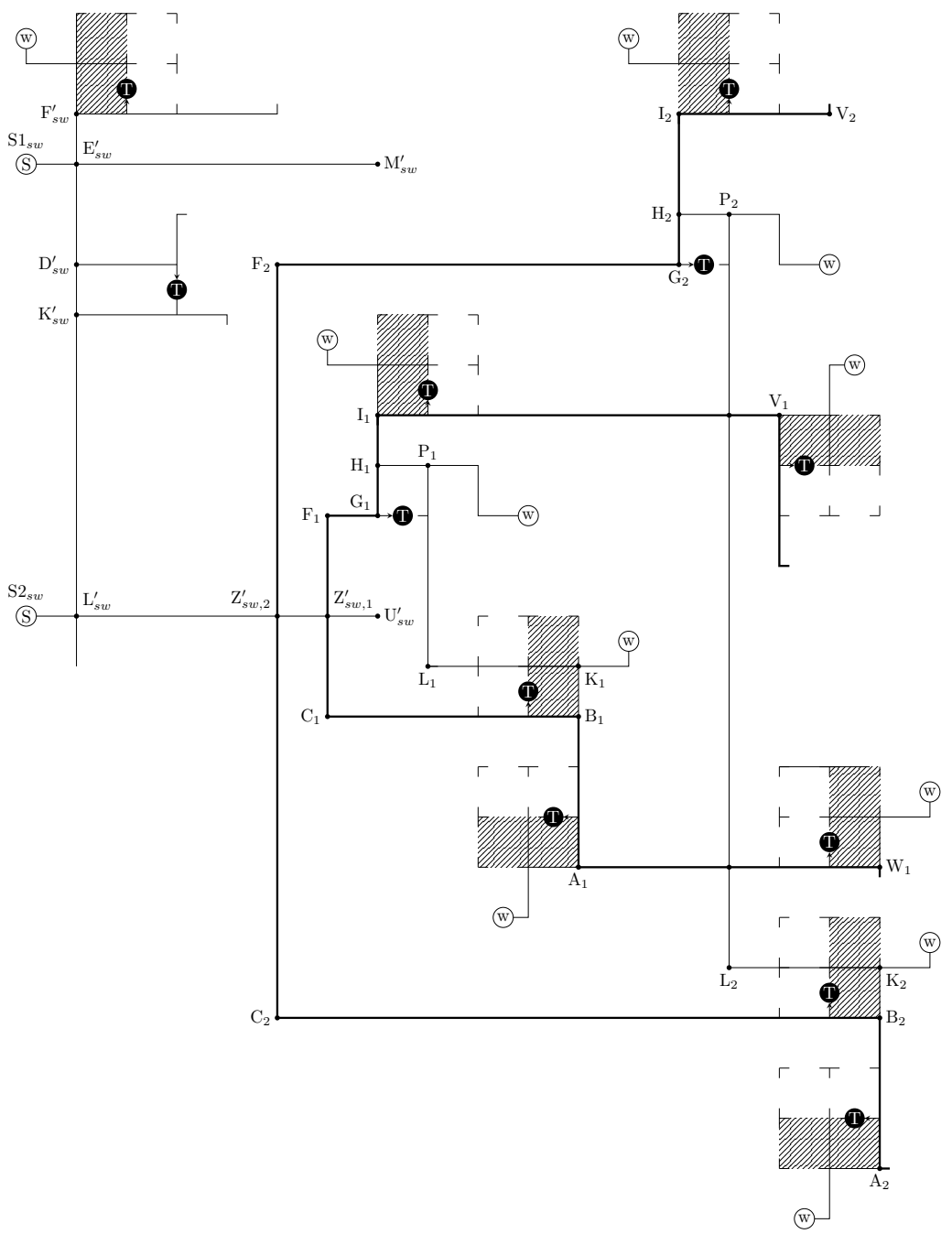

Figure 106. W-win lanes crossing with $\mathrm{W}$-switch.

Lemma 25. Let $i=1$ or 2 . Suppose Figure 106 starts from $\left(\bigcirc_{f}, \boldsymbol{\bullet}_{f}\right)=\left(B_{i}, A_{i}\right)$ in WHITE's turn. If $\bullet_{b} \notin S 2_{s w} U_{s w}^{\prime},(O, \bullet)=\left(B_{i}, A_{i}\right) \stackrel{*}{\rightarrow}\left(V_{i}, I_{i}\right)$, else WHITE must lose.

Proof. When $\boldsymbol{\bullet}_{b} \notin \mathrm{S} 2_{s w} \mathrm{U}_{s w}^{\prime}$ (i.e., $\boldsymbol{\bullet}_{b} \in \mathrm{S} 2_{s w} \mathrm{U}_{s w}$ ), Lemma 14 forces the claimed moves since Figure 106's gadget over $\overline{\mathrm{A}_{i} \mathrm{~B}_{i}} \cup \overline{\mathrm{B}_{i} \mathrm{C}_{i}} \cup \overline{\mathrm{C}_{i} \mathrm{~F}_{i}} \cup \overline{\mathrm{F}_{i} \mathrm{G}_{i}} \cup \overline{\mathrm{G}_{i} \mathrm{I}_{i}} \cup \overline{\mathrm{I}_{i} \mathrm{~V}_{i}} \cup \overline{\mathrm{B}_{i} \mathrm{~K}_{i}} \cup \overline{\mathrm{K}_{i} \mathrm{~L}_{i}} \cup \overline{\mathrm{L}_{i} \mathrm{P}_{i}} \cup$ $\overline{\mathrm{P}_{i} \mathrm{H}_{i}}$ is congruent with that in Figure 101.

Suppose $\bullet_{b} \in \mathrm{S} 2_{s w} \mathrm{U}_{s w}^{\prime}$ and $\left(\mathrm{O}_{f}, \boldsymbol{\bullet}_{f}\right)=\left(\mathrm{B}_{i}, \mathrm{~A}_{i}\right)$ for WHITE to move. The first turn must be $\left(\mathrm{O}_{f}, \bullet_{f}\right)=\left(\mathrm{B}_{i}, \mathrm{~A}_{i}\right) \rightarrow\left(\mathrm{C}_{i}, \mathrm{~A}_{i}\right)$ by Lemma 14 . Bounded- $\bullet$ can march $\mathrm{L}_{s w}^{\prime} \rightarrow \mathrm{Z}_{i, s w}^{\prime}$ to block it as $\left(\left(\mathrm{O}_{f}, \boldsymbol{\bullet}_{f}, \mathbf{\bullet}_{b}\right)=\left(\mathrm{C}_{i}, \mathrm{~A}_{i}, \mathrm{~L}_{s w}^{\prime}\right) \rightarrow\left(\mathrm{C}_{i}, \mathrm{~A}_{i}, \mathrm{Z}_{s w, 1}^{\prime}\right)\right.$. After that, the $\mathrm{O}_{f}$ must go to either $\mathrm{B}_{i}$ or non- $\mathrm{B}_{i}$ and lose to BLACK's winning repetition (free $\bullet$, free $\mathrm{O}$ ) $=\left(\mathrm{W}_{i}, \mathrm{~B}_{i}\right) \rightarrow$ $\left(\mathrm{A}_{i}, \mathrm{C}_{i}\right) \rightarrow\left(\mathrm{A}_{i}, \mathrm{~B}_{i}\right) \rightarrow\left(\mathrm{W}_{i}, \mathrm{~B}_{i}\right)$, or BLACK's winning position $\left(\mathrm{A}_{i}, \mathrm{C}_{i}\right) \rightarrow\left(\mathrm{A}_{i}, \mathrm{C}_{i} \mathrm{~B}_{i}\right) \rightarrow$ $\left(\mathrm{K}_{i}, \mathrm{C}_{i} \mathrm{~B}_{i}\right)$ by Lemma 13.

\subsection{Winning Lanes and Gates}

WHITE's winning lanes are Figure 99's one-way roads except taking Figure 106's bridge structures near the switches. WHITE's winning gates are Figure 40's B-weak points. 


\section{EXPTIME Hardness}

Theorem 2 (Theorem 1, formal). The $\mathrm{G}_{2}$-game is log-space many-one reducible to the custodian capture game of R.1-R.5 over the $n \times n$ square board and the winning number five.

Proof. We assume that Definition 1's $G_{2}$-game solves a dichotomy (i.e., no draw) problem in EXPTIME. We prove that the $G_{2}$-game's winner, say BLACK is the custodial capture game's one. The same $\alpha$ never appears again in the same player's turn. Thus, the positions of the bounded men under correspondence also do not do it under correspondence $X_{i}=\mathrm{TRUE} \Leftrightarrow \mathrm{W}$-switch $\left[X_{i}\right]=\mathrm{ON}$ and $Y_{i}=\mathrm{TRUE} \Leftrightarrow \mathrm{B}$-switch $\left[Y_{i}\right]=\mathrm{ON}$.

We embed a $G_{2}$ game's configuration by Figure 107's mapping to the $n \times n$ board's custodian capture game. It combines the W-field on the upper half and the dual B-field on the lower half. We will explain only W-field. It simulates the WHITE's one turn in the $G_{2}$ game by a series of alternating turns in the custodian capture game, beginning from the $\mathrm{W}$-start gate on the left and ending in the B-start gate on the right. The players must mimic an escape-and-chase match (to avoid immediate defeat) and proceed along continuous solid lines. Lemma 14 allows the crossing of the lines with no interference. Lemma 17's dual starts WHITE's turn from the W-start gate. At the W-branches above the $\mathrm{W}$-start, Lemma 15 allows WHITE to choose his variable, say $X_{1}$, to change. Lemma 23 changes the state of the $\mathrm{W}$-switch $\left[X_{1}\right]$ (or unchanged by his choice), and Lemma 16 merges the branches at the right $\mathrm{W}$-joins to guide WHITE to the last $\mathrm{W}$-branch above the B-start, where he can declare his win at the end of his turn. The declaration brings him to the top W-branches to pick his winning term, say $A_{3}$ in Figure 108, and walk along as described in Figure 109: Visit the right side of the W-switch $\left[X_{1}\right]$ (Figure $105^{\prime}$ s $Z^{\prime}$ ), the left side of W-switch $\left[X_{2}\right]$ (Figure 105's Z), and the right side of the B-switch $\left[Y_{1}\right]$ (the dual Figure's $\left.\mathrm{G}^{\prime}\right)$. Lemma 25 passes or blocks the passenger BLACK by the truth value of the literals $\left\{X_{1}, \neg X_{2}, Y_{1}\right\}$ in $A_{3}$. Consequently, WHITE can win by choosing the TRUE term $A_{i}$ when his winning DNF condition becomes TRUE; WHITE must lose if his choice is wrong.

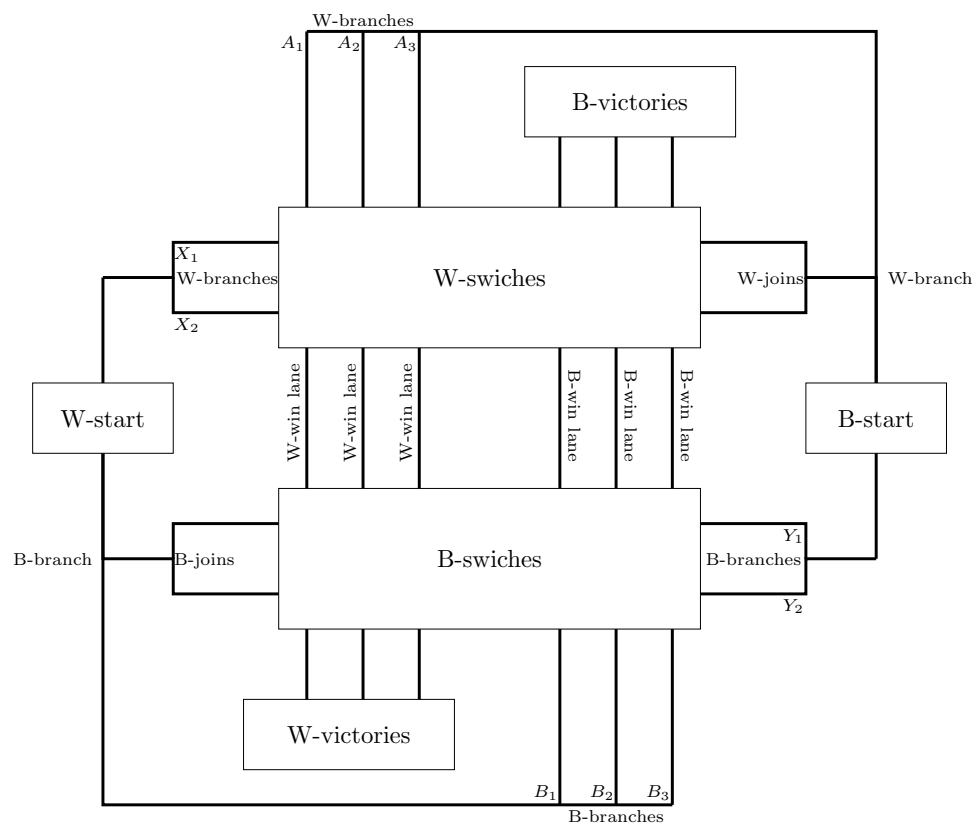

Figure 107. Custodian capture game for $G_{2}$. 


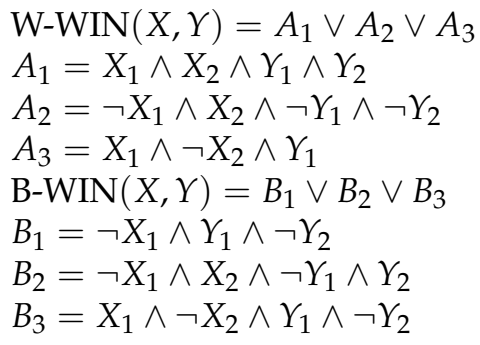

Figure 108. An instance of $G_{2}$.

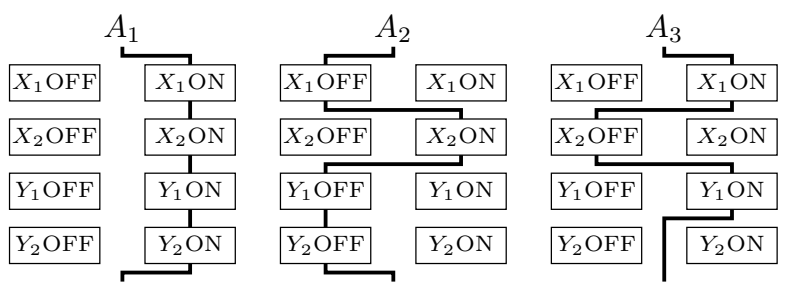

Figure 109. W-winning lanes.

Notice that Figure 106 may cascade more than two lanes for implementing the WHITE's 12-term DNF. Alternatively, the two cascades are enough for it by using a branch-switch[ $\left[\mathrm{V}_{i, 1}\right]$-join-branch-switch[ $\left.\mathrm{V}_{i, 2}\right]$-join-. $\cdots$ structure, where $V_{i, j}$ is $V_{i}$ 's occurrence $\left(V_{i}=X_{i}\right.$ or $\left.Y_{i}\right)$ in a term $A_{j}$. We can use one of the two W-win lanes to force WHITE to choose the same state over these switches as follows: Let him choose ON or OFF and walk along with the route passing through $Z^{\prime}$ or $Z$ of these $X_{i}$-switches $\left(G^{\prime}\right.$ or $G$ of the $Y_{i}$-switches), respectively, to make sure that the states of these switches are ON (resp. OFF).

Figure 107 maps a $G_{2}$-game instance into the custodian capture game of size $O(|X|+$ $|Y|)$ within at most $O(\log n)$ computational space in the following manner. Each W-switch corresponds to each occurrence of the $X$-variables. The $\mathrm{W}$-branches on the left towards the W-switches include a binary tree of $2|X|$ leaves, where each pair connects to the left and right entrances of a $\mathrm{W}$-switch. Similarly, the right $\mathrm{W}$-junctions form a binary tree of the paired leaves connecting to the W-switches' exits. Each $\mathrm{W}$-winning lane begins from a B-branch on the top, passing through switches, and ending at a $\mathrm{W}$-victory gate.

Lemmas 1, 3, 4, 6, 8, 10 and 18 demand each player to move only the single free man or one of many bound men. They will justify Lemma 12 to consider only the free and bounded men rather than all men on the board. Lemmas 13-17, 21 and 25 look at only the two free men's moves in their winning repetitions; Lemmas 19, 20 and 22-24 only the four men inside a single switch. These Lemmas should count the bounded mens' positions in the other switching gadgets and apply Lemma 12. However, we can justify it as follows and complete the current theorem's proof.

ACRM proved that any two-person board game might not change the winner even if a turn player allows the opponent (or the game-solving machine) to select the player's moves to remain just one winning move. Any winning position possesses Definition 3's unique winning one in the ACRW's extension of the game. We may assume it for the current custodian capture game as well.

A mini-game starts when $\left(\mathrm{O}_{f}, \bigcirc_{f}, \mathrm{O}_{b}, \mathbf{O}_{b}\right)=\left(\mathrm{E}, \mathrm{L}, \mathrm{E}^{\prime}, \mathrm{L}^{\prime}\right)$ occurs in one switch and ends when it does in another one. During the mini-game, Let $t$ count the number of moves, $\pi(t)=\left(\pi_{f}(t), \pi_{b}(t)\right)=\left(\pi_{f, \mathrm{o}}(t), \pi_{f, \bullet}(t), \pi_{b, \mathrm{o}}(t), \pi_{b, \bullet}(t)\right)$ be the $\{$ free, bounded $\}$ $\times\{\bigcirc, \bigcirc\}$ men's positions at a given time $t$, and $\# \pi(t)$ the number of times visiting the position $\pi$ from the beginning until the time $t$ of the mini-game. It is a non-decreasing function reset to 0 when a new game starts. Suppose the opponent promises to take the deterministic (predetermined) moves against the player's unique winning ones. To not delay the game, WHITE should skip $\pi(t) \rightarrow \pi(t+k)$ in a repetition $\pi(t) \rightarrow \pi(t+1) \rightarrow$ $\cdots \rightarrow \pi(t+k)=\pi(t)$ of his winning positions. Notice that the above Lemmas' repetitions could never get out the free men from the correponding Figures' entrances by Lemma 13.

Suppose that BLACK promises to let $\boldsymbol{\bigcirc}_{b}$ mimic $\bigcirc_{b}$. She moves $\boldsymbol{\bigcirc}_{b}$ to the correspond- 
ing place in the same switch each time WHITE has moved $O_{b}$, deducing $\forall t, \# \pi_{b, \bullet}(t) \leq$ $\# \pi_{b, o}(t)$. Lemmas 22 and 24 assure BLACK's survival over the switches since $\boldsymbol{\bullet}_{b} \equiv \mathrm{O}_{b}$ under this promise. The proofs of these Lemmas make $\boldsymbol{\bullet}_{b}$ to mimic $\mathrm{O}_{b}$ and keep $\boldsymbol{\bullet}_{b} \equiv \mathrm{O}_{b}$, too. Consequently, WHITE must choose $\pi=\pi(\operatorname{argmax}(t))$ for $\operatorname{argmax}(t)=$ $\max \left\{t \mid \pi_{f}(t)=\pi_{f}\right\}$ during the BLACK's winning repetitions except when BLACK might be the first to violate R.4. However, $\bullet_{b}$ 's move would never incur it since $\# \pi_{b, \bullet}(t)=3$ occurs only after $\# \pi_{b, o}(t)=3$ in the precedent WHITE's turn. Similarly, $\bullet_{f}$ 's one would never do it since \# $\#$ • $(t) \leq \# \pi_{\circ}(t)$ by induction on $t$ as argued in Lemma 12: In a repetition $\pi_{1, f} \rightarrow \cdots \rightarrow \pi_{k, f}=\pi_{1, f} \rightarrow \cdots \rightarrow \pi_{k, f}=\pi_{1, f} \rightarrow \cdots \rightarrow \pi_{k, f}$ with $\pi_{i, f}=\pi_{f}\left(t_{i+(j-1) k}\right)$ at the $j$ th iteration, if $1 \leq \forall i \leq k$, \# $\pi_{\bullet}\left(t_{i}\right) \leq \# \pi_{\circ}\left(t_{i}\right)$ then $1 \leq \forall i \leq k, 1 \leq \forall j \leq 3, \# \pi_{\bullet}\left(t_{i+(j-1) k}\right) \leq \# \pi_{\circ}\left(t_{i+(j-1) k}\right)$. Consequently, Lemma 12 holds even for the position $\pi(t)=\left(\pi_{f}(t), \pi_{b}(t)\right)$ of the two free and all bounded men in the above Lemmas.

\section{Conclusions}

We have proved that a custodian capture game over the $n \times n$ square board is EXPTIME hard. It allowed for capturing multiple men in a line at once like Japanese HasamiShogi. Ludus Latrunculorum, Tafl games, and many others do not, whose computational complexity over $n \times n$ board is still unknown. Our proof relied heavily on the no-repetition rule R.4, which might establish even EXPSPACE-completeness by analyzing the bounded men's trajectories. The custodian capture game allowing repetition of positions might be EXPTIME-complete like Chess [8].

Author Contributions: Conceptualization, T.T.; Formal analysis, T.T., F.I., M.N. and N.K.; Investigation, T.T., F.I., M.N. and N.K.; Methodology, T.T., M.N. and N.K.; Visualization, F.I.; Writing-original draft, T.T., F.I. and N.K.; Writing — review \& editing, T.T. All authors have read and agreed to the published version of the manuscript.

Funding: This research received no external funding.

Data Availability Statement: Not applicable.

Conflicts of Interest: The authors declare no conflict of interest.

\section{References}

1. Bell, R.C. Board and Table Games from Many Civilizations; Courier Corporation: Chelmsford, MA, USA, 1979 ; Volume 1.

2. Parlett, D. The Oxford History of Board Games; Oxford University Press: Oxford, UK, USA, 1999.

3. Murray, H.J.R. A History of Chess; Clarendon Press: Oxford, UK, 1913.

4. Murray, H.J.R. A History of Board-Games Other than Chess; Clarendon Press: Oxford, UK, 1952.

5. Franklin, M.J. Asiatick Researches, Or, Transactions of the Society Instituted in Bengal, for Inquiring Into the History and Antiquities, the Arts, Sciences, and Literature of Asia; Taylor \& Francis: Oxfordshire, UK, 2000; Volume 2.

6. Shotwell, P. A Form of Tibetan Mig-Mang From the West. Available online: https://studylib.net/doc/6753073/a-form-oftibetan-mig-mang-from-the-west (accessed on 23 February 2021).

7. Helmfrid, S. Hnefatafl-the Strategic Board Game of the Vikings. Available online: http://hem.bredband.net/b512479/ (accessed on 23 February 2021).

8. Fraenkel, A.S.; Lichtenstein, D. Computing a perfect strategy for $\mathrm{n} \times \mathrm{n}$ chess requires time exponential in $\mathrm{n}$. J. Combin. Theory Ser. A 1981, 31, 199-214. [CrossRef]

9. Robson, J.M. N by N checkers is Exptime complete. SIAM J. Comput. 1984, 13, 252-267. [CrossRef]

10. Robson, J.M. The complexity of Go. In Proceedings of the IFIP 9th World Computer Congress, Paris, France, 19-23 September 1983.

11. Arora, S.; Barak, B. Computational Complexity: A Modern Approach; Cambridge University Press: Cambridge, UK, 2009.

12. Hearn, R.A.; Demaine, E.D. Games, Puzzles, and Computation; CRC Press: Boca Raton, FL, USA, 2009.

13. Lichtenstein, D.; Sipser, M. Go is polynomial-space hard. J. ACM (JACM) 1980, 27, 393-401. [CrossRef]

14. Crâşmaru, M.; Tromp, J. Ladders are PSPACE-complete. In Proceedings of the International Conference on Computers and Games, Hamamatsu, Japan, 26-28 October 2000; Springer: Hamamatsu, Japan, 2000; pp. 241-249.

15. Wolfe, D. Go endgames are PSPACE-hard. More Games No Chanc. 2002, 42, 125-136.

16. Saffidine, A.; Teytaud, O.; Yen, S.J. Go Complexities. In Advances in Computer Games; Springer: Berlin/Heidelberg, Germany, 2015; pp. 76-88. 
17. Zhang, Z. A Note on Computational Complexity of Kill-all Go. arXiv 2019, arXiv:1911.11405.

18. Robson, J.M. Combinatorial games with exponential space complete decision problems. In Proceedings of the International Symposium on Mathematical Foundations of Computer Science, Praha, Czechoslovakia, 3-7 September 1984; pp. 498-506.

19. Chandra, A.K.; Stockmeyer, L.J. Alternation. In Proceedings of the 17th Annual Symposium on Foundations of Computer Science (sfcs 1976), Houston, TX, USA, 25-27 October 1976; pp. 98-108.

20. Stockmeyer, L.J.; Chandra, A.K. Provably difficult combinatorial games. SIAM J. Comput. 1979, 8, 151-174. [CrossRef]

21. Adachi, H.; Kamekawa, H.; Iwata, S. Shogi on $\mathrm{n} \times \mathrm{n}$ board is complete in exponential time. Trans. IEICE 1987, 70, 1843-1852.

22. Zhang, Z. A Note on Hardness Frameworks and Computational Complexity of Xiangqi and Janggi. arXiv 2019, arXiv:1904.00200.

23. Mishiba, S.; Takenaga, Y. QUIXO is EXPTIME-complete. Inf. Process. Lett. 2020, 162, 105995. [CrossRef]

24. Aida, S.; Crasmaru, M.; Regan, K.; Watanabe, O. Games with uniqueness properties. Theory Comput. Syst. $2004,37,29-47$. [CrossRef] 